\title{
Role of a phenolic pool in the conversion of m-cresol to aromatics over HY and HZSM-5 zeolites
}

\author{
Anh T. To and Daniel E. Resasco*
}

Keywords: HY and HZSM-5 zeolites, m-cresol, aromatic, phenolic pool 


\begin{abstract}
The conversion of m-cresol over two acidic zeolites has been studied on a_micro-pulse reaction system in the temperature range of $400-600^{\circ} \mathrm{C}$. The zeolites were HZSM-5 and HY and had the same $\mathrm{Si} / \mathrm{Al}$ ratio of 40 . At $400^{\circ} \mathrm{C}$ both zeolites were found to be highly efficient in trapping irreversibly the phenolic reactant. As the temperature increased, the extent of phenolic trapping was lower, resulting in a reduced amount of carbonaceous deposits, while the coke became more graphitic. While m-cresol only produced isomers and transalkylation vapor phenolic products, the vast majority of the amount of injected $\mathrm{m}$-cresol resulted in condensed products on the surface that lead to the formation of a phenolic pool. Therefore, the aromatic hydrocarbons that dominate the reactor output originate from the cracking of the surface pool. At low reaction temperature, toluene is the major pool cracking product, but, at higher temperatures the selectivity to benzene increases. Independent measurements of toluene and xylene conversion, under the same conditions, indicate that these changes in selectivity are not due to secondary reactions of toluene to benzene, but rather a change in the cracking pattern of the surface pool.
\end{abstract}




\section{Introduction}

Biomass pyrolysis, combined with catalytic upgrading, is considered as a promising strategy for production of renewable fuels [1-4]. Among a number of promising catalytic upgrading strategies [5], zeolites play a major role, either when they are used in-situ (catalytic pyrolysis) [6-8], or in a separate bed to treat the vapors leaving the pyrolysis reactor [9-11]. In comparison with the hydrotreating processes, typically used for hydrodeoxygenation of pyrolysis oil [12, 13], zeolite upgrading can be conducted at a much lower pressure (typically near atmospheric) and with a much lower requirement of $\mathrm{H}_{2}$, which may represent significant advantages in terms of capital investment and operation costs $[11,14]$. Compared to other options, co-processing partially upgraded bio-oil fractions in a conventional oil refinery is perhaps the most promising strategy for the incorporation of renewable feedstocks in the fuel pool [15]. Using the existing infrastructure of a refinery would greatly help reducing investment costs. Moreover, the enormous capacity of typical refining units is an obvious advantage for boosting the production of bio-fuels in large scale. Among the potential injection points for incorporation of bio-oil fractions in a refinery, the fluid catalytic cracking (FCC) is a prospective candidate. It has been proposed that due to its large capacity and flexibility for processing different type of feedstocks, FCC could co-process significant volumes of bio-fuels [14,16-19].

Acidic zeolites, such as HY and H-ZSM-5 are important constituents of FCC catalysts. Therefore, it is important to study the interaction of the oxygenated compounds that are typically present in pyrolysis oils and vapors with zeolites [20-24]. As shown in previous studies [25], the major reactions of phenolic compounds over acidic zeolites are isomerization and transalkylation, which mostly produce isomeric and alkylated phenolic compounds but very low yields of aromatics. They tend to undergo condensation reactions, which form heavy ethers, which in turn are precursors for coke formation [21, 23-25]. Molecular adsorption of these phenolics on both Bronsted (BAS) and Lewis acid sites (LAS) lead to the formation of carbonaceous deposits and catalyst deactivation [17, 26, 27]. In a previous study [28], we showed that a bare H-beta zeolite was very efficient in capturing m-cresol molecules irreversibly, quickly saturating the surface. We pointed out that this initial capture of phenolics could not be detected using a continuous flow reactor, in which product analysis is done under steady state with the catalyst surface covered by the phenolic compounds. Therefore, to understand the initial interaction of phenolics with the fresh zeolite, it is necessary to use a pulse reaction system. In this contribution, the conversion of $\mathrm{m}$-cresol, as a representative of phenolic compounds, has been studied over HY and HZSM-5 zeolites using a micropulse reaction system. To quantify the interaction of the phenolic compounds with the clean catalyst surface at different temperatures, a detailed quantitative analysis was made of the fractions of the feed in each pulse that are captured by the zeolite, desorb, or react to form products. 


\section{Experimental}

\subsection{Materials}

The two zeolites used as catalysts in this study were provided by Zeolyst International. The two samples had different structure, but identical Si/Al ratio. One of them was a dealuminated HY (CBV780, Si/Al=40) with FAU structure and the other was a $\mathrm{NH}_{4} \mathrm{ZSM}-5$ (CBV8014, Si/Al=40) with MFI structure. In order to obtain the H-form of the ZSM-5 sample, the as-received CBV8014 material was treated under $100 \mathrm{sccm}$ flow of air with a linear heating ramp of $2^{\circ} \mathrm{C} / \mathrm{min}$ to $600^{\circ} \mathrm{C}$ and held at this temperature for $6 \mathrm{~h}$. Before reaction, the catalysts were pelletized and sieved into 90-250 $\mu$ m particles. m-Cresol (99\%+, from SAFC), toluene and o-xylene ( $99 \%+$ from Sigma Aldrich) were used as feed without further purification.

\subsection{Catalytic measurements}

The conversion of m-cresol was evaluated in a micro-pulse reactor at atmospheric pressure of $\mathrm{He}$ carrier gas. In each experiment, a $100 \mathrm{mg}$ catalyst sample was pretreated under $200 \mathrm{sccm} \mathrm{He}$ flow at $600^{\circ} \mathrm{C}$ for $1 \mathrm{~h}$. After pretreatment, the temperature was adjusted to the selected reaction temperature $\left(400-600^{\circ} \mathrm{C}\right.$ range) while the $\mathrm{He}$ flow rate was lowered to $20 \mathrm{sccm}$. When the reactor temperature was stable $\left(+/-0.5^{\circ} \mathrm{C}\right)$, a vaporized m-cresol diluted in $\mathrm{He}$ at a concentration of $5 \times 10^{-7} \mathrm{~mol} / \mathrm{cm}^{3}$ was sent over the catalyst bed. The total amount of m-cresol in each pulse was $0.15 \mu \mathrm{mol}$. Also, pulse experiments with a 10 -fold more concentrated stream of $\mathrm{m}$-cresol in $\mathrm{He}(11.3 \mathrm{~mol} \%)$, and hence a larger amount of $\mathrm{m}$-cresol $(1.5 \mu \mathrm{mol})$ in each pulse, were carried out to study the catalyst deactivation. The reactor output was analyzed on-line using an HP5890 gas chromatograph (GC), equipped with an HP-1 column and a flame ionization detector (FID).

Reactions of toluene ( $1.9 \mathrm{~mol} \%$ of toluene in $\mathrm{He}, 0.24 \mu \mathrm{mol}$ toluene/pulse) and o-xylene (1.6 mol\% of toluene in $\mathrm{He}, 0.21 \mu \mathrm{mol}$ toluene/pulse) were also carried out at $600^{\circ} \mathrm{C}$ in order to investigate the possible secondary reactions of the aromatic products derived from the m-cresol conversion. In this case, the product analysis was carried out on the GC-FID using an HP$\mathrm{PLOT} / \mathrm{Al}_{2} \mathrm{O}_{3} /$ “S” column.

During the 1-hour intervals between each pulse, the catalyst was exposed to continuous flow of He. Products were identified and quantified by using mixtures of reference compounds of calibrated concentrations. All conversion values reported in this work have been corrected for the small contribution of non-catalytic thermal conversion at each corresponding temperature. To quantify the extent of thermal conversion in these blank runs, pulses of m-cresol, toluene, and o-xylene were injected over an inert bed (acid-washed glass beads, $100 \mu \mathrm{m}$ in diameter) under the same reaction conditions as those used with the catalysts. As expected, thermal conversion of m-cresol increased with reaction temperature, but in all cases it was very small, reaching only 
a maximum of $0.8 \%$ at $600^{\circ} \mathrm{C}$. Thermal conversion of toluene and o-xylene was negligible $(<$ $0.1 \%)$.

\subsection{Temperature programmed oxidation (TPO) and decomposition (TPDe) of the carbonaceous deposits}

TPO was used after each reaction to quantify the amount of carbonaceous deposits remaining on the catalyst. For this, the same reactor tube containing the spent catalyst was connected to a TPO system equipped with a Cirrus mass spectrometer (MS) to measure the evolution of $\mathrm{CO}_{2}(\mathrm{~m} / \mathrm{z}=44)$ during the temperature ramp. To oxidize the carbonaceous deposits, a stream of $20 \mathrm{sccm}$ of $\mathrm{He} / \mathrm{O}_{2}\left(5 \%\right.$ volume $\left.\mathrm{O}_{2}\right)$ was used. Following reaction and after the furnace temperature was stable at $50^{\circ} \mathrm{C}$, the reactor was heated linearly with a $10{ }^{\circ} \mathrm{C} / \mathrm{min}$ ramp up to $700^{\circ} \mathrm{C}$ and held at this temperature until the $\mathrm{CO}_{2}$ signal reached the baseline. Since oxygen was used in excess, the deposits were oxidized completely to $\mathrm{CO}_{2}$ and only trace amounts of $\mathrm{CO}$ were observed. To quantify the amount and yield of the carbonaceous deposit, the $\mathrm{CO}_{2}$ signal $(\mathrm{m} / \mathrm{z}=44)$ was calibrated with $100 \mu \mathrm{l}$ pulses of pure $\mathrm{CO}_{2}$.

TPDe of the carbonaceous deposits on the spent catalyst was also carried out to study the activity of the remaining phenolic pool formed during the $\mathrm{m}$-cresol reaction. A Microvision Plus MS, scanning over a $1-200 \mathrm{~m} / \mathrm{z}$ range at a speed of 15 cycles/min, was connected to the reactor outlet to detect product evolution, both, during pulses of m-cresol through the catalyst bed and subsequently during the TPDe of the spent catalyst. After 10 pulses of m-cresol $(1.5 \mu \mathrm{mol} \mathrm{m}$ cresol/pulse) over 50 (or 100) $\mathrm{mg}$ catalyst-bed at $400^{\circ} \mathrm{C}$ (or $500^{\circ} \mathrm{C}$ ), the catalyst was flushed for $20 \mathrm{~min}$ to remove all weakly adsorbed species. Then, for the TPDe, a $5^{\circ} \mathrm{C} / \mathrm{min}$ linear heating ramp was initiated; when reaching the target temperature $\left(500-600^{\circ} \mathrm{C}\right)$ it was held constant until all signals reached the baseline. Pulses of toluene, benzene, and methane with known amounts were sent through an inert bed to the MS to quantify the evolution rate of the major products observed during TPDe.

\section{Results and discussion}

\subsection{Product evolution and formation of carbonaceous deposits as a function of temperature}

The conversion of diluted m-cresol, concentration $5 \times 10^{-7} \mathrm{~mol} / \mathrm{cm}^{3} \mathrm{~m}$-cresol in He, over HY and HZSM-5 zeolites at varying temperatures $\left(400-600^{\circ} \mathrm{C}\right)$ was investigated in a micro-pulse reactor. Due to the high dilution and small size of the pulse, the amount of m-cresol injected in a pulse was much smaller than the amount of catalyst (i.e., catalyst/reactant mass ratio is $\sim 6,000$ per pulse). As a result, the deactivation of the catalyst in these experiments was negligible at all temperatures. 
Figure 1 shows the accumulated yields of products together with unconverted m-cresol that leaves the reactor (i.e., total output) after 9 pulses and the remaining carbonaceous deposits measured by TPO of the spent catalyst also after 9 pulses of m-cresol over the catalysts (HY and HZSM-5 zeolites) at different temperatures. It is important to note that, depending on the temperature, different fractions of the feed remained trapped in the catalyst bed. For instance, at $400^{\circ} \mathrm{C}$, no products or unconverted reactants come out of the catalyst bed; that is, the entire pulse was trapped and counted here as "carbonaceous deposits". As the reaction temperature increased, the total output increased, including products together with a small fraction of unconverted m-cresol. By contrast, the yield of carbonaceous deposits decreased, although even at the highest temperature investigated $\left(600^{\circ} \mathrm{C}\right)$ about $60 \mathrm{wt} \%$ of the feed remained trapped (adsorbed or forming coke) in the catalyst bed. When accounting for the carbon retained on the catalyst, the mass balance for the reactions was very good (that is, over 90\%). The high efficiency of the zeolite to trap phenolics explains the rapid catalyst deactivation typically observed in continuous flow experiments [26-28].

As summarized in Fig. 2, the m-cresol deoxygenation was very effective on these fresh catalysts and the main products leaving the catalyst were benzene, toluene, and xylenes (BTX) at all temperatures. As the reaction temperature increased, the product yield increased. It is seen that the O-containing phenolic products started to come off at temperatures above $450^{\circ} \mathrm{C}$, together with unreacted $\mathrm{m}$-cresol. The distribution of these phenolic products includes cresol isomers, xylenols, and heavier phenolic species. Phenol was only observed as a minor product over HZSM-5 at $600^{\circ} \mathrm{C}$.

As shown in Fig. 3, while only aromatics were seen in the reactor output at $450^{\circ} \mathrm{C}$, phenolics accounted for more than $20 \%$ of the total output at $600^{\circ} \mathrm{C}$. It is well known that isomerization and transalkylation of cresols readily occurs over acidic zeolites at moderate reaction temperature [24,29-31]. However, due to the strong adsorption, all of these phenolic compounds remain trapped inside the zeolite until temperature is high enough to let them desorb. It is important to emphasize that this effective trapping is more clearly evident in the small-pulse experiments conducted in this study than in a typical continuous-flow experiment. In the pulse experiment, the clean catalyst is in an inert environment before being exposed to a small amount of reactant; by contrast, in the continuous-flow experiment, phenolic compounds most likely saturate the majority of the adsorption sites. At higher reaction temperatures desorption of phenolics is possible, leading to an increase in yield and selectivity in total output. Hence, it is clear that, at high temperatures, along with a higher extent of deoxygenation to aromatic products, a lower extent of phenolic trapping contributes to the observed reduction in carbonaceous deposits.

Another important effect of reaction temperature is the changes in product distribution within the BTX aromatics (see Fig. 3). At low reaction temperature, toluene was the major aromatic product; but, when the temperature increased, the selectivity to toluene decreased and 
benzene increased. Instead, the selectivity to the xylene isomers increased to a maximum at an intermediate temperature, i.e. $500^{\circ} \mathrm{C}$, and then decreased as the reaction temperature increased. This variation in selectivity may be due to a combination of several possible reactions, which requires additional analysis and discussion. For instance, since toluene was the major product from the conversion of $\mathrm{m}$-cresol at the lower temperature and benzene appeared at higher temperatures, one could infer that a direct dehydroxylation of this phenolic compound might explain the selectivity changes [17]. Further reactions of toluene, such as the disproportionation to xylenes and benzene [32], and dealkylation to benzene [33] would be consistent with the observed evolution of products (higher benzene/toluene ratio at higher temperatures, as shown in Fig. 4). However, as explained below, the production of aromatic products from m-cresol does not occur via a direct deoxygenation pathway, but rather through the formation and cracking of a surface pool of oxygenated aromatic, that is, a phenolic pool.

\subsection{TPO Analysis of carbonaceous deposits on the spent catalyst}

It is worth noting that the observed trend for the formation of carbonaceous deposits with reaction temperature during the conversion of m-cresol over zeolites is in direct contrast with the trend typically observed with hydrocarbons. For instance, Fig. 5 compares the amounts of the deposits (as measured by TPO) at varying reaction temperature observed during reaction of $\mathrm{m}$ cresol and n-hexane over HY zeolite. Two important aspects can be emphasized in this comparison.

First, it is remarkable that even though a much lower amount of m-cresol was sent over the catalyst compared to that of n-hexane (i.e. $1.3 \mu \mathrm{mol}$ vs. $80 \mu \mathrm{mol}$ in total, respectively), the amount of carbonaceous deposits resulting from cresol was much larger. During n-hexane conversion on $\mathrm{HY}$, the amount of coke deposits was less than $0.2 \mu \mathrm{mol}$ below $500^{\circ} \mathrm{C}$ and barely reached $0.85 \mu \mathrm{mol}$ at $600^{\circ} \mathrm{C}$, which represents less than $0.2 \%$ of the total $\mathrm{C}$ fed $(20$ pulses $\mathrm{x} 4$ $\mu \mathrm{mol}$ hexane/pulse $\mathrm{x} 6 \mathrm{C} /$ hexane). By contrast, during $\mathrm{m}$-cresol conversion, the average amount of carbon retained at different temperatures ranged from 6 to $9 \mu \mathrm{mol}$ of $\mathrm{C}$, representing a retention of 63 to $95 \%$ of the total amount of $C(9.45 \mu \mathrm{mol})$ injected over the catalyst. Similar measurements over the HZSM-5 zeolite gave comparable results; that is, the carbon retention with the m-cresol feed was much higher than with n-hexane. This trend seems to be a common one for all the acidic zeolites, as previously implied [26-28].

Second, the typical trend [34,35] of increasing carbonaceous deposits as a function of temperature observed with paraffins (Fig. 5b) or aromatic hydrocarbons [36] is not observed with phenolics, but rather the opposite trend is observed (Fig. 5a). That is, the formation of a surface phenolic pool is more effective at lower temperatures. Interestingly, while the methanol conversion to hydrocarbons (MTH) over zeolites is also believed to proceed via formation of a hydrocarbon pool mechanism [37-39], coke formation does increase with reaction temperature [40], which is contrary to our observations with m-cresol. This contrasting trend might indicate 
that the nature of the pool of carbonaceous deposits formed by m-cresol conversion is different from those by hydrocarbon cracking or MTH.

In the case of hydrocarbon cracking, coke deposits are formed from a series of intermolecular reactions such as oligomerization of olefins, H-transfer, cyclization, and alkylation, which generate polyaromatic products that strongly adsorb on the acid sites, causing deactivation of the active site and pore blockage [41]. Likewise, it is generally accepted that in MTH the pool of aromatic and olefinic species builds up on the surface by methylation reaction $[38,39]$. Subsequent cracking of the olefinic pool and dealkylation of the aromatic pool yield the hydrocarbon products, while hydride transfer and cyclization are responsible for the formation of polyaromatic species that lead to coke. When the reaction temperature increases, hydride transfer and cyclization reactions facilitate the formation of coke in both, hydrocarbon cracking and MTH reactions; this coke is composed of highly condensed polyaromatic hydrocarbons [40, 41]. By contrast, in the conversion of oxygenated aromatic compounds, such as phenolics and furanics, the formation of the oligomeric species proceeds via condensation. An evidence of this condensation is the diphenylether species observed in the products [24]. Oligomeric compounds have also been proposed to form via Diels-Alder condensation during the conversion of furan over HZSM-5 [42], with benzofuran and dibenzofuran as important intermediates. Further condensation with furan and alkylation with allylic products from furan decarbonylation can produce larger oligomeric oxygenated species. In fact, subsequent extraction and analysis of the carbonaceous deposits have confirmed the presence of considerable amounts of $\mathrm{O}$ in the spent catalyst. That is, the pool formed by reaction of phenolic or furanic compounds contains oxygenated aromatic hydrocarbons, i.e a phenolic pool produced by condensation reactions.

The shape of the TPO profiles can shed more light into the nature of the carbonaceous deposits from m-cresol conversion. For instance, Fig. 6 illustrates the $\mathrm{CO}_{2}(\mathrm{~m} / \mathrm{z}=44)$ evolution profiles from the spent HZSM-5 zeolite after 9 pulses of $\mathrm{m}$-cresol at different reaction temperatures. It is clear that, as the reaction temperature increases, the fraction of carbonaceous deposits that can be oxidized at lower temperatures (i.e. below $500^{\circ} \mathrm{C}$ ) drops significantly. At the same time, it is seen that the $\mathrm{CO}_{2}$ evolution peak shifts to higher temperatures (i.e. from 550 to $620^{\circ} \mathrm{C}$ ) with increasing reaction temperature. This shift indicates the formation of more refractory coke deposits (i.e more graphitic). A very similar trend was observed for the spent HY zeolite, in line with previous reports on the reactivity of carbonaceous deposits toward oxygen with increasing furan conversion temperatures over HZSM-5 [42].

\subsection{Formation and decomposition of the carbonaceous deposits}

The trends observed in the pulse and TPO experiments indicate that the phenolic pool that forms at low reaction temperatures might still be active for further reaction and could release fragments of the pool into the gas phase when heated at higher temperatures. In turn, the remaining fraction of the pool should become a more graphitic coke. In order to test this 
possibility, the reactivity of the phenolic pool produced at low reaction temperature by TPDe of the spent catalyst. In this experiment, the reactor outlet was directly connected to a Microvision Plus MS, scanning over a $1-200 \mathrm{~m} / \mathrm{z}$ range, to detect the evolution of fragments of the pool under a linear heating ramp. For this experiment, the concentration of the $\mathrm{m}$-cresol pulses $(5 \mathrm{x}$ $10^{-6} \mathrm{~mol} / \mathrm{cm}^{3} \mathrm{~m}$-cresol in $\mathrm{He}$ ) was higher than those used in the previous experiment, so the amount injected in this pulse was ten times higher $(1.5 \mu \mathrm{mol} \mathrm{m}$-cresol $)$, to cause a more evident deactivation and to make the product evolution from the catalyst more easily detectable in the MS detector.

Before the TPDe, ten $1.5-\mu \mathrm{mol}-\mathrm{m}$-cresol pulses were injected at $400^{\circ} \mathrm{C}$ over the HZSM-5 sample. The evolution of water $(\mathrm{m} / \mathrm{z}=18)$, cresols $(\mathrm{m} / \mathrm{z}=107)$, and toluene $(\mathrm{m} / \mathrm{z}=91)$ was monitored by MS. As shown in Fig. 7, even though the amount of m-cresols increased 10 times relative to the previous experiments (section 3.1.), no evolution of products or unreacted phenolics came out of the catalyst bed for the $100 \mathrm{mg}$ sample (Fig. 7a). When the catalyst amount was reduced to $50 \mathrm{mg}$ (Fig. 7b), most of the cresol pulse still remained trapped during the initial 3-4 injections, but started appearing in larger amounts during the subsequent pulses. It is clear that the strong adsorption and perhaps pore blockage by cresol reaches a saturation after injection of about $100 \mu \mathrm{mol} / \mathrm{g}$ cat.

The analysis of the evolution of water during each pulse provides further insight about the interaction of m-cresol and the zeolite. First, no water evolution was observed during the

initial few pulses but started appearing after the $3^{\text {rd }}$ pulse over the $100 \mathrm{mg}$ bed (Fig. 7a) and after the $2^{\text {nd }}$ pulse over the $50 \mathrm{mg}$ bed (Fig. $7 \mathrm{~b}$ ). Second, it is important to note that water started to evolve much earlier than the unconverted m-cresol. Water production increased to a maximum intensity and slightly decreased in subsequent pulses. That is, it is clear that during the first few pulses on the clean catalyst surface, m-cresol adsorbs non-dissociatively on either BAS or LAS [26,27], but as the surface concentration increases during later pulses, the gas-phase m-cresol starts reacting with the surface phenolic species via condensation, producing multi-phenyl species and water, leading to a phenolic surface pool [24]. These oxygenated aromatic species remain trapped inside the zeolite and continue growing by further condensation when subsequent $\mathrm{m}$-cresol pulses are sent, eventually leading to catalyst deactivation. This deactivation results in the observed decrease in the extent of condensation reactions and water evolution, as shown in Fig. $7 b$.

When the amount of catalyst was doubled (Fig. 7a), more sites were available for mcresol to adsorb non-dissociatively and distribute across the catalyst surface. Hence, condensation reaction of $\mathrm{m}$-cresol in the pulse with surface phenolic species only occurred on later pulses. In this case, deactivation was observed later, due to a larger amount of sample for the same pulse size.

\subsection{Distribution of products evolved from decomposition of the surface pool}


To investigate the reactivity of the surface pool, the species trapped on the spent catalyst were heated in a linear temperature ramp, while the product evolution was monitored by online MS. As illustrated in Fig. 8 a-c for the HY zeolite and Fig. 9 a-c for the HZSM-5 zeolite, after 10 pulses of $\mathrm{m}$-cresol at $400^{\circ} \mathrm{C}$, the TPDe showed that considerable amounts of hydrocarbons evolved from both spent catalysts. These products include benzene $(\mathrm{m} / \mathrm{z}=78)$, toluene $(\mathrm{m} / \mathrm{z}=$ $91)$ and methane $(\mathrm{m} / \mathrm{z}=16)$, indicating that the carbonaceous deposits formed at the low reaction temperature $\left(400^{\circ} \mathrm{C}\right)$ were still active for further reaction and product evolution at higher temperatures. Remarkably, no phenolic compounds were detected as decomposition products, but only hydrocarbons. These results contrast with those observed in the pulse experiments, in which the selectivity to phenolic products increased with reaction temperature. That is, during the pulse experiments, the observed phenolic products do not derive from decomposition of the carbonaceous deposits, but rather from the direct isomerization reactions of m-cresol. At higher reaction temperatures, the irreversible adsorption of phenolic compounds is reduced, i.e. less of them are trapped by the zeolite, and hence, more of them are released.

The TPDe products from the phenolic pool formed during reaction at $500^{\circ} \mathrm{C}$ are shown in Fig. $8 \mathrm{~d}$ and $9 \mathrm{~d}$. After reaction at $500^{\circ} \mathrm{C}$, the reactor temperature was stabilized at $400^{\circ} \mathrm{C}$ before starting the linear heating ramp; so, this TPDe profile can be directly compared to that from the pool formed on the sample during reaction at $400^{\circ} \mathrm{C}$ (Fig. $8 \mathrm{c}$ and $9 \mathrm{c}$ ). It can be observed that the initial evolution of hydrocarbons at temperature lower than $500^{\circ} \mathrm{C}$ disappeared in the TPDe of the phenolic pool formed at $500^{\circ} \mathrm{C}$. That is, the pool formed at a given temperature is still active for further reaction, but only at a higher temperature.

The amounts of each compound evolved from the TPDe experiments included in Fig. 8a$\mathrm{c}$ and $9 \mathrm{a}-\mathrm{c}$ are summarized in Table 1. Yields of aromatic produced from decomposition of the pool are also compared with those in the pulse experiments. Even though the aromatic yield from the decomposition of the pool was slightly lower than the amount produced in the pulse reaction, the trends observed in the aromatic production with temperature, as well as the effect of the zeolite structure were very similar. That is, more aromatic products were produced at higher temperatures, and the HZSM-5 zeolite resulted in higher yields of aromatic than the HY zeolite. These consistent results further confirm that the aromatics produced in both cases, that is, during pulses or by heating the residual surface fragments proceed from a common source, the phenolic pool.

The toluene production rate has a maximum at around $500-520^{\circ} \mathrm{C}$, while the peaks for benzene and methane production rate appear at higher temperature $\left(575-590^{\circ} \mathrm{C}\right)$. As a result, the benzene/toluene ratio increases with reaction temperature. These results are consistent with the benzene/toluene ratio observed in the pulse experiment (Fig. 4). The immediate conclusion from this trend would be that as temperature increases, benzene and methane are produced from dealkylation of toluene, which was formed earlier, at lower temperature. However, further experiments showed that this was not the case. In fact, the literature shows that direct toluene 
dealkylation forming benzene and methane is typically occurs in $\mathrm{H}_{2}$ atmosphere, either thermally [43] or catalyzed by metal oxides [44, 45]. By contrast, over zeolites the transformation of toluene mainly proceeds via a bimolecular disproportionation that produces benzene and xylene $[46,47]$, which are not the major products observed in our experiments. In fact in the pulse experiments, small amounts of xylenes were observed, which might indicate the secondary toluene conversion via disproportionation. However, the selectivity to benzene was always much higher than that to xylenes. Moreover, no xylenes were detected in the TPDe experiments, showing that the secondary reaction of toluene is insignificant. Another difference is the drastic effect of temperature in our results, which contrast with the small changes in selectivity to benzene typically observed in the toluene transformation over USY zeolites [36]. In general, light hydrocarbons are produced from the toluene conversion (mostly $\mathrm{C} 3$ and $\mathrm{C} 4$ hydrocarbons) with very small amounts of methane, contrarily to the products we observe here.

To further confirm that the distribution of toluene, benzene, and methane produced from the phenolic pool in our pulse experiments do not derive from secondary reactions, another set of experiments was conducted. Pulses of toluene and o-xylene were injected over the two zeolites investigated (HY and $\mathrm{HZSM}-5$ ) at $600^{\circ} \mathrm{C}$ at the same carrier gas velocity used in the TPDe experiments. As shown in Tables 2 and 3, methane was only observed in trace amounts. That is, dealkylation of methylated benzenes to methane was negligible. The main reactions of toluene and o-xylene conversion observed at $600^{\circ} \mathrm{C}$ were disproportionation and isomerization, which is entirely consistent with the previous literature [32, 36, 46-49]. Our own previous study of the conversion of $\mathrm{m}$-cresol over Beta zeolite also showed that demethylation of m-cresol to phenol was insignificant [28]. Therefore, it is safe to conclude that the enhanced production of benzene and methane at high temperature should mainly come from the reaction of the phenolic pool rather than a secondary dealkylation reaction.

Examining the TPDe profiles obtained with different isothermal holds at various temperatures (Fig. 8a-c and 9a-c) helps us analyze the reactivity of the phenolic pool in further detail. One can expect that the production rates of hydrocarbons evolved from the pool should depend on both, the decomposition rate constant and the amount of phenolic pool that can react at that temperature. During the isothermal periods, the rate constants do not change, while the pool is continuously consumed. Hence, production rates of hydrocarbons decrease during the holding period following a first order decay, as seen for all hydrocarbons. The distribution of products shows that toluene is the favored product from cracking of the phenolic pool at the lower temperatures, while the pool at higher temperature (i.e. a more refractory pool) produces more benzene and methane.

To further demonstrate that the product distribution represents differences in cracking of the pool rather than different extents of secondary reactions, the TPDe of the phenolic pool formed at $400{ }^{\circ} \mathrm{C}$ was carried out over different amount of catalyst (i.e. $50 \mathrm{mg}$ and $100 \mathrm{mg}$ ). The product distributions are compared in Table 1. It can be observed that when the catalyst amount 
was doubled, more hydrocarbons were produced from the phenolic pool upon TPDe, as expected. However, the TPDe profile and more importantly the ratio of benzene/toluene were the same in the two cases. This result shows that the composition of the phenolic pool was similar in both cases and that there was no enhanced production of secondary products, which supports the concept that the benzene/toluene ratio is determined by the reactivity of the pool, not an interconversion of toluene to benzene.

Scheme I summarizes the proposed reaction pathway in the conversion of phenolics to aromatics. That is, phenolics undergo three types of primary reactions on zeolites, none of them includes the production of deoxygenated hydrocarbons. They are isomerization, transalkylation, and condensation. The first two produce phenolic products while the last one results in the formation of a surface pool, which is the true precursor of the aromatics observed as products. These hydrocarbons are mostly aromatics and are formed by cracking and $\mathrm{H}$-transfer reactions of the surface pool, which does not produce oxygenated compounds. Interestingly, the distribution of hydrocarbon products as a function of temperature is more a result of the different cracking of the surface pool rather than of secondary conversion undergone by the products. A similar phenomenon has been recently observed during the conversion of glucose on HZSM-5 [50]. In that case, conversion of a mixture of ${ }^{13} \mathrm{C}$-labeled and unlabeled glucose showed a high extent of $\mathrm{C}$ scrambling in the aromatic products, but no scrambling in the oxygenated products. The authors suggested that direct dehydration and bond cleavage of glucose were responsible for the observed oxygenated products, but these oxygenates also condensed to form a surface pool, which subsequently cracked evolving aromatic compounds.

\subsection{Effect of the zeolite type on the interaction with m-cresol}

Even though the reaction of m-cresol over HY and HZSM-5 zeolites showed similar trends with reaction temperature, there were considerable differences in the conversion of $\mathrm{m}$ cresol over HY compared to that with HZSM-5 due to the differences in their pore structure. The results in Fig. 1 show that m-cresol was trapped more efficiently and formed more carbonaceous deposits on HY than that on HZSM-5. As a result, more products were released from HZSM-5 than from HY, but the selectivities to aromatic and phenolic products were similar for the two zeolites, as shown in Fig. 3.

An interesting difference is observed in the distribution of aromatic products. The selectivity to benzene was higher on HZSM-5 than on HY (Fig. 3). Significant differences in aromatic yields and selectivities were observed not only in the pulse experiment, but also in the TPDe of the phenolic pool, as shown in Table 1. With the same amount of m-cresol adsorbed on $50 \mathrm{mg}$ of the catalysts, the TPDe of the spent HZSM-5 yielded six times more aromatics than the TPDe of the spent HY zeolite. Furthermore, the benzene/toluene ratio was also higher from the TPDe of HZSM-5 than HY, consistent with the results of the pulse experiments (Fig. 4). The similarities in the aromatic production trend in the pulse experiment and TPDe of the phenolic 
pool over HY and HZSM-5 zeolites consolidate the hypothesis of aromatic production from the phenolic pool.

In the pulse experiments of section 3.1, deactivation was negligible because the amount of m-cresol in each pulse $(0.15 \mu \mathrm{mol})$ was very small compared to the amount of catalyst. Therefore, in order to compare the stability of the two zeolites and study the changes in product yield upon catalyst deactivation, the concentration of the $\mathrm{m}$-cresol pulse $(11.3 \mathrm{~mol} \%)$, and hence the amount of m-cresol in each pulse, was increased 10 times to $1.5 \mu \mathrm{mol}$, and only $50 \mathrm{mg}$ of catalyst was used. Figure 10 shows the evolution of product yields and unreacted $\mathrm{m}$-cresol as a function of pulse number from the reaction of m-cresol at $500^{\circ} \mathrm{C}$ over $\mathrm{HY}$ and HZSM-5 zeolites. It is evident that the deactivation is much more pronounced on HY than on HZSM-5. Over HZSM-5, the product yields almost did not change with pulse number, while over HY zeolite, the total output gradually increased with pulse number due to a larger amount of phenolics and unreacted $\mathrm{m}$-cresol. This trend indicates that less phenolic compound get trapped as the catalyst deactivates. The yield of aromatic products only decreased slightly because they are produce from the surface pool, rather than from a reaction on a vacant catalyst site. At an even higher extent of deactivation, the selectivity to aromatic products decreased considerably. That is, aromatics are major products in the output in the $1^{\text {st }}$ pulse, but phenolics become dominant in the $10^{\text {th }}$ pulse. With the higher m-cresol concentration used in this set of experiments, the fast deactivation of the HY zeolite is probably due catalyst pore blockage. By contrast, on HZSM-5 although $\mathrm{m}$-cresol is also trapped to a significant extent, the catalyst deactivation is not apparent since the cracking of the phenolic pool continues operating and yielding aromatics as the dominant products.

It is known that the amount and deactivating effects of carbonaceous deposits on zeolites strongly depend on their pore structure $[41,51,52]$. The HY zeolite, with a relatively large void/aperture size ratio [53], has a higher trapping ability than ZSM-5, which has similar cavity and channel sizes. Steric constraints in ZSM-5 restrict the formation of carbonaceous deposits, which proceeds via bimolecular reactions and produce smaller coke molecules compared to that in $\mathrm{Y}$ zeolite. While the coke in Y zeolite contains large polyaromatic hydrocarbons, the coke in ZSM-5 usually has 1 or 2 aromatic rings with connected alkyl chains. Coke formation in conversion of oxygenated compounds also depends on the zeolite structure [50]. Large pore zeolites, such as Y, have shown to result in large extents of coke deposition, while intermediate pore zeolites, such as ZSM-5, have a lower tendency for coke formation and produce high aromatic yields. Similarly, in this work, the higher trapping ability of HY zeolite would result in increased formation of carbonaceous deposits compared to HZSM-5. Moreover, the phenolic pool formed on HZSM-5 might have a smaller size than that formed on HY due to steric constraints. As a result, more separate pools can be formed on HZSM-5 than on HY zeolite and the same amount of m-cresol trapped may lead to higher amounts of aromatic hydrocarbons produced from the cracking of the phenolic pool. By contrast, larger phenolic pools on the HY 
zeolite might cause pore blockage that deactivates the catalyst quickly, inhibiting the rate of further trapping of phenolics.

\section{Conclusions}

The micro-pulse reaction system is particularly suited to investigate the interactions of phenolic compounds with the bare zeolite surface. Interesting phenomena have been recognized in this study, which could not have been observed on a conventional continuous flow reaction system. Both zeolites (HZSM-5 and HY) were found to be highly efficient in trapping irreversibly a significant fraction of the reactant. Major products detected at the reactor output were aromatic hydrocarbons, while phenolic products, formed by isomerization and transalkylation reactions, were minor because most of them remained trapped on the catalyst via condensation reactions that lead to the formation of a phenolic pool. Interestingly, the pool is still active for reaction at higher temperatures producing aromatic and light hydrocarbons, mostly methane. With increased reaction temperatures, enhanced cracking to aromatics, and a lower extent of trapping of phenolics reduced the amount of carbonaceous deposits, while the coke became more graphitic. Having both the same Si/Al ratio, the HZSM-5 zeolite showed a better performance than $\mathrm{HY}$ in terms of production of aromatics and resistance to catalyst deactivation.

\section{Acknowledgements}

Financial support from the Department of Energy Grant DE-EE0006287 of the Bioenergy Technology Office CHASE program is greatly appreciated. Funding for a doctoral scholarship for ATT was provided by Phillips 66. 


\section{References}

[1] G.W. Huber, S. Iborra, A. Corma, Chem. Rev., 106 (2006) 4044.

[2] D.E. Resasco, S. Crossley, AlChE J., 55 (2009) 1082.

[3] S.K. Hoekman, Renewable Energy, 34 (2009) 14.

[4] Q. Zhang, J. Chang, T. Wang, Y. Xu, Energy Convers. Manage., 48 (2007) 87.

[5] T.N. Pham, D. Shi, D.E. Resasco, Appl. Catal., B: Environ., 145 (2014)10.

[6] M.C. Samolada, A. Papafotica, I.A. Vasalos, Energy Fuels, 14 (2000) 1161.

[7] P.T. Williams, N. Nugranad, Energy, 25 (2000) 493.

[8] T.S. Nguyen, M. Zabeti, L. Lefferts, G. Brem, K. Seshan, Biomass Bioenergy, 48 (2013) 100.

[9] S. Wan, C. Waters, A. Stevens, A. Gumidyala, R.E. Jentoft, L. Lobban, D.E. Resasco, S. Crossley, R.G. Mallinson, Prepr. Pap.-Am. Chem. Soc., Div. Energy Fuels 59 (2014) 346.

[10] T.S. Nguyen, M. Zabeti, L. Lefferts, G. Brem, K. Seshan, Biomass Bioenergy, 48 (2013) 100.

[11] P.T. Williams, P.A. Horne, Fuel, 74 (1995) 1839.

[12] D. C. Elliott, T. R. Hart, G.G. Neuenschwander, L.J. Rotness, A.H. Zacher, Env. Progr. \& Sust. Energy 28 (2009) 441.

[13] E. Furimsky, Appl. Catal., A: Gen., 199 (2000) 147.

[14] P.M. Mortensen, J.D. Grunwaldt, P.A. Jensen, K.G. Knudsen, A.D. Jensen, Appl. Catal., A: Gen., 407 (2011) 1.

[15] K. Tong, M.J. Gleeson, G. Rong, F. You, Biomass Bioenergy, 60 (2014) 108. 
[16] G.W. Huber, A. Corma, Angew. Chem. Int. Ed., 46 (2007) 7184.

[17] I. Graça, F.R. Ribeiro, H.S. Cerqueira, Y.L. Lam, M.B.B. de Almeida, Appl. Catal., B: Environ., 90 (2009) 556.

[18] A.A. Lappas, S. Bezergianni, I.A. Vasalos, Catal. Today, 145 (2009) 55.

[19] F. de Miguel Mercader, M.J. Groeneveld, S.R.A. Kersten, N.W.J. Way, C.J. Schaverien, J.A. Hogendoorn, Appl. Catal., B: Environ., 96 (2010) 57.

[20] J. Jae, G.A. Tompsett, A.J. Foster, K.D. Hammond, S.M. Auerbach, R.F. Lobo, G.W. Huber, J. Catal., 279 (2011) 257.

[21] A.G. Gayubo, A.T. Aguayo, A. Atutxa, R. Aguado, J. Bilbao, Ind. Eng. Chem. Res., 43 (2004) 2610.

[22] A.G. Gayubo, A.T. Aguayo, A. Atutxa, R. Aguado, M. Olazar, J. Bilbao, Ind. Eng. Chem. Res., 43 (2004) 2619.

[23] J.D. Adjaye, N.N. Bakhshi, Biomass Bioenergy, 8 (1995) 131.

[24] P.D. Chantal, S. Kaliaguine, J.L. Grandmaison, Appl. Catal., 18 (1985) 133.

[25] X. Zhu, R.G. Mallinson, D.E. Resasco, Appl. Catal., A: Gen., 379 (2010) 172.

[26] I. Graça, J.D. Comparot, S. Laforge, P. Magnoux, J.M. Lopes, M.F. Ribeiro, F.R. Ribeiro, Appl. Catal., A: Gen., 353 (2009) 123.

[27] I. Graça, J.D. Comparot, S. Laforge, P. Magnoux, J.M. Lopes, M.F. Ribeiro, F.R. Ribeiro, Energy Fuels, 23 (2009) 4224.

[28] A. Ausavasukhi, Y. Huang, A.T. To, T. Sooknoi, D.E. Resasco, J. Catal., 290 (2012) 90.

[29] F.E. Imbert, N. Gnep, M. Guisnet, J. Catal., 172 (1997) 307.

[30] F.E. Imbert, S. Gnep, M. Guisnet, Catal. Lett., 49 (1997) 121. 
[31] F.E. Imbert, M. Guisnet, S. Gnep, J. Catal., 195 (2000) 279.

[32] P. Beltrame, P.L. Beltrame, P. Carniti, L. Forni, G. Zuretti, Zeolites, 5 (1985) 400.

[33] C.L. Thomas, J. Hoekstra, J.T. Pinkston, J. Am. Chem. Soc., 66 (1944) 1694.

[34] R.F. De Santos, E.A. Urquieta-González, Braz. J. Chem. Eng., 15 (1998).

[35] Y.X. Zhao, G.R. Bamwenda, W.A. Groten, B.W. Wojciechowski, J. Catal., 140 (1993) 243.

[36] S. Al-Khattaf, Energy Fuels, 20 (2006) 946.

[37] W. Wang, Y. Jiang, M. Hunger, Catal. Today, 113 (2006) 102.

[38] S. Ilias, A. Bhan, ACS Catal., 3 (2012) 18.

[39] S. Ilias, A. Bhan, J. Catal., 290 (2012) 186.

[40] G.V. Echevskii, K.G. Ione, G.N. Nosyreva, G.S. Litvak, Appl. Catal., 43 (1988) 85.

[41] M. Guisnet, P. Magnoux, C. Canaff, Stud. Surf. Sci. Catal., 28 (1986), 701.

[42] Y.T. Cheng, G.W. Huber, ACS Catal., 1 (2011) 611.

[43] S.E. Shull, A.N. Hixson, Ind. Eng. Chem. Process Des. Dev., 5 (1966) 146.

[44] T. Doumani, Ind. Eng. Chem., 50 (1958) 1677.

[45] J. Haber, E. Zienkiewicz, Appl. Catal., 10 (1984) 267.

[46] Y. Xiong, P.G. Rodewald, C.D. Chang, J. Am. Chem. Soc., 117 (1995) 9427.

[47] F. Chen, G. Coudurier, C. Naccache, Stud. Surf. Sci. Catal., 49 (1989), 1387.

[48] M. Guisnet, N.S. Gnep, S. Morin, Microporous Mesoporous Mater., 35-36 (2000) 47.

[49] A. Iliyas, S. Al-Khattaf, Appl. Catal., A: Gen., 269 (2004) 225.

[50] T.R. Carlson, J. Jae, G.W. Huber, ChemCatChem, 1 (2009) 107.

[51] M. Guisnet, P. Magnoux, Appl. Catal., 54 (1989) 1. 
[52] M. Guisnet, P. Magnoux, D. Martin, Stud. Surf. Sci. Catal., 111 (1997), 1.

[53] F.L. Raúl, in: S.M. Auerbach, K.A. Carrado, P.K. Dutta (Eds.), Handbook of Zeolite Science and Technology, CRC Press, 2003, pp. 65-90 
(a)

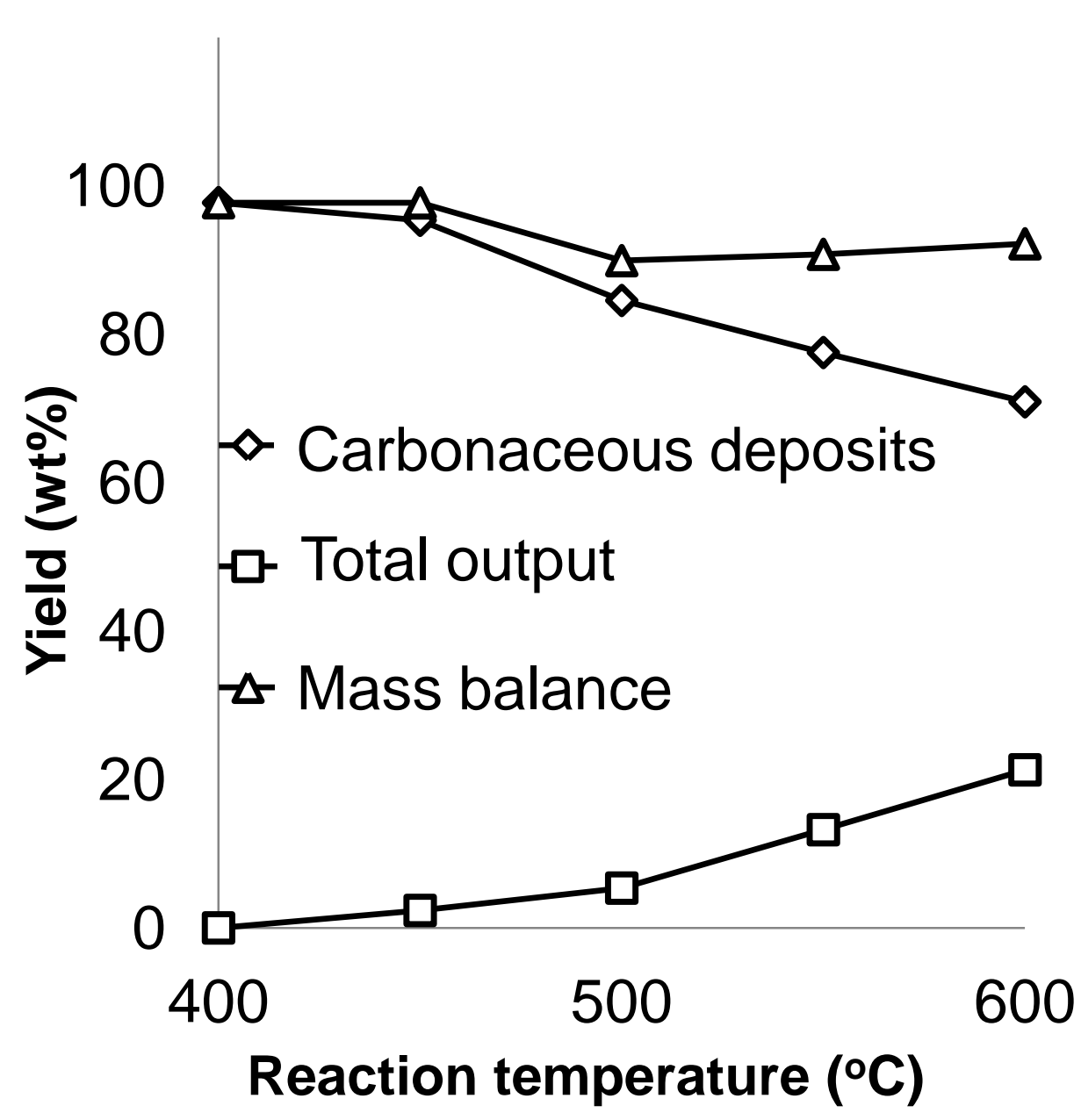

(b)

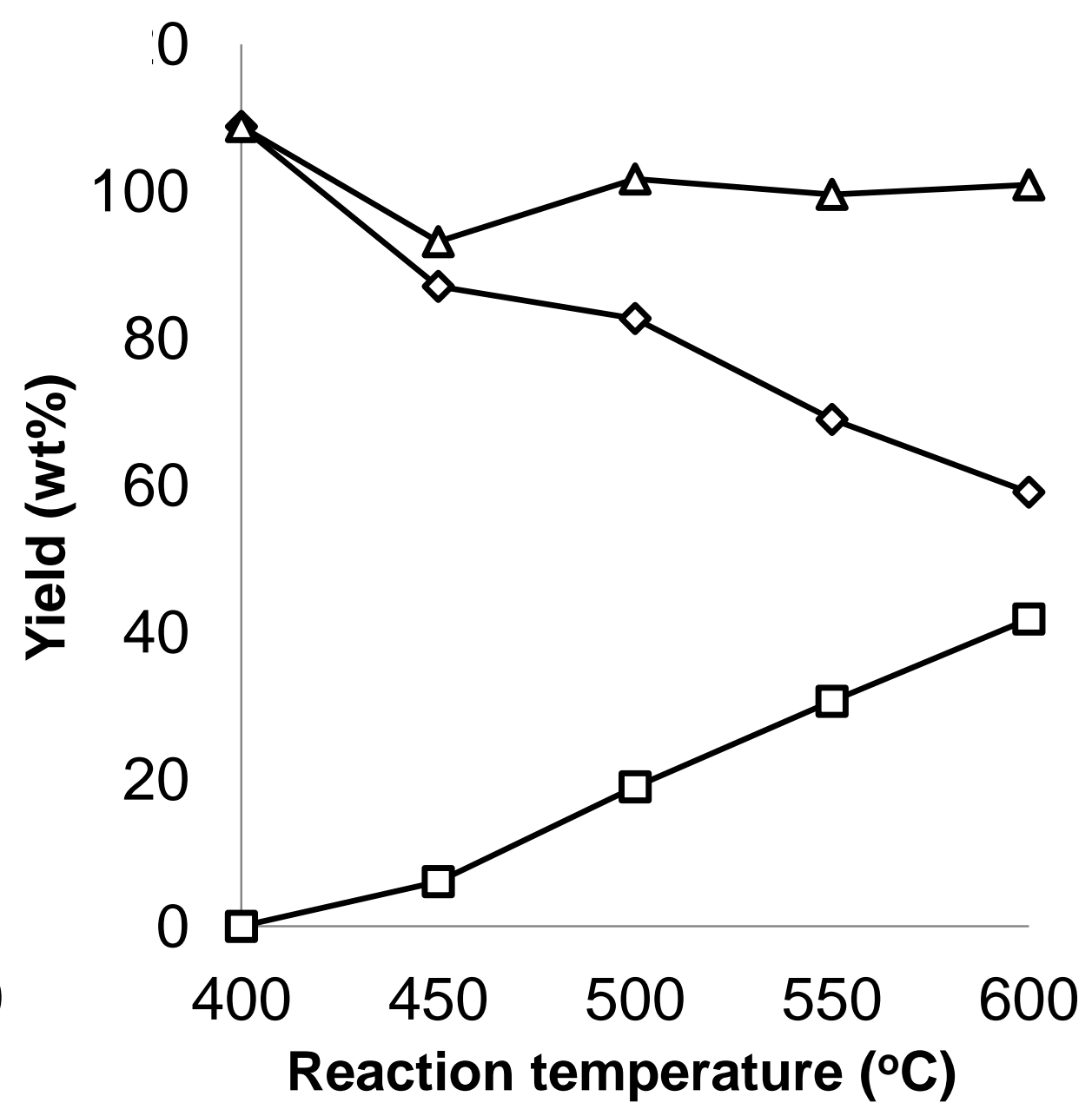

Figure 1. Accumulated yields of total output and carbonaceous deposit after 9 pulses of $\mathrm{m}$ cresol over (a) HY and (b) HZSM-5 zeolites at different temperatures 
(a)

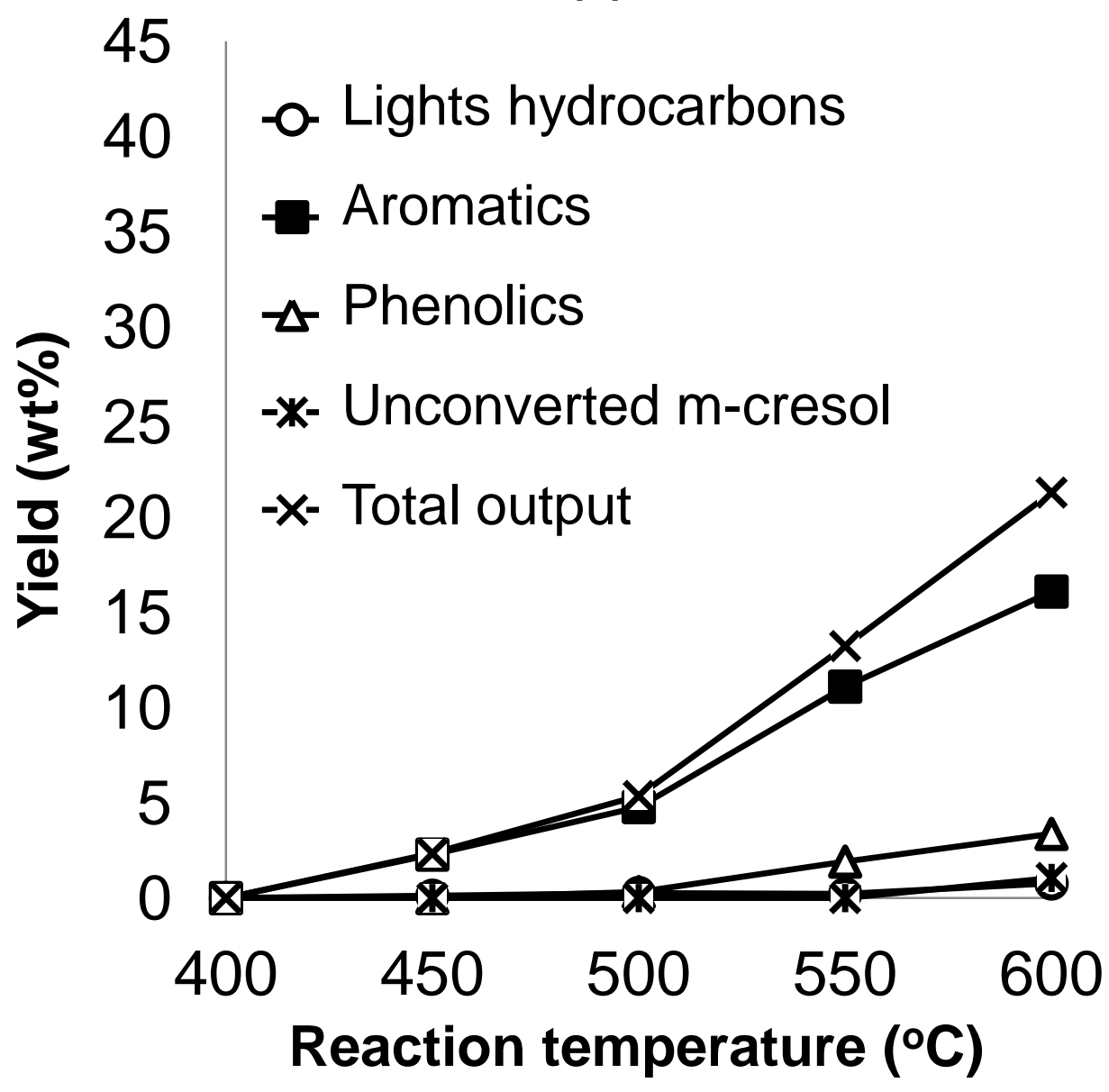

(b)

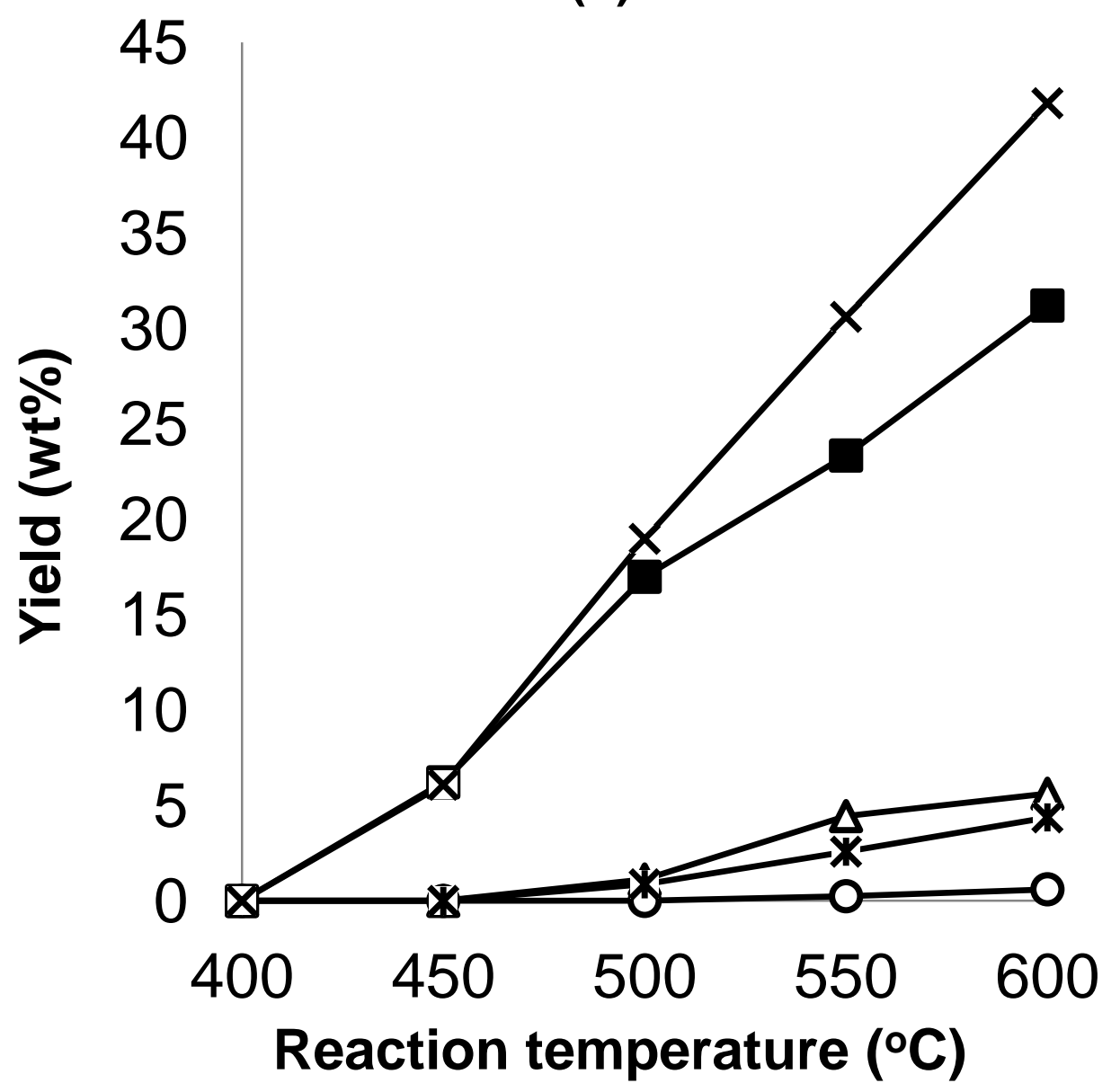

Figure 2. Accumulated yield of products and unconverted m-cresol evolved from 9 pulses of m-cresol over (a) HY and (b) HZSM-5 zeolites at different temperatures 


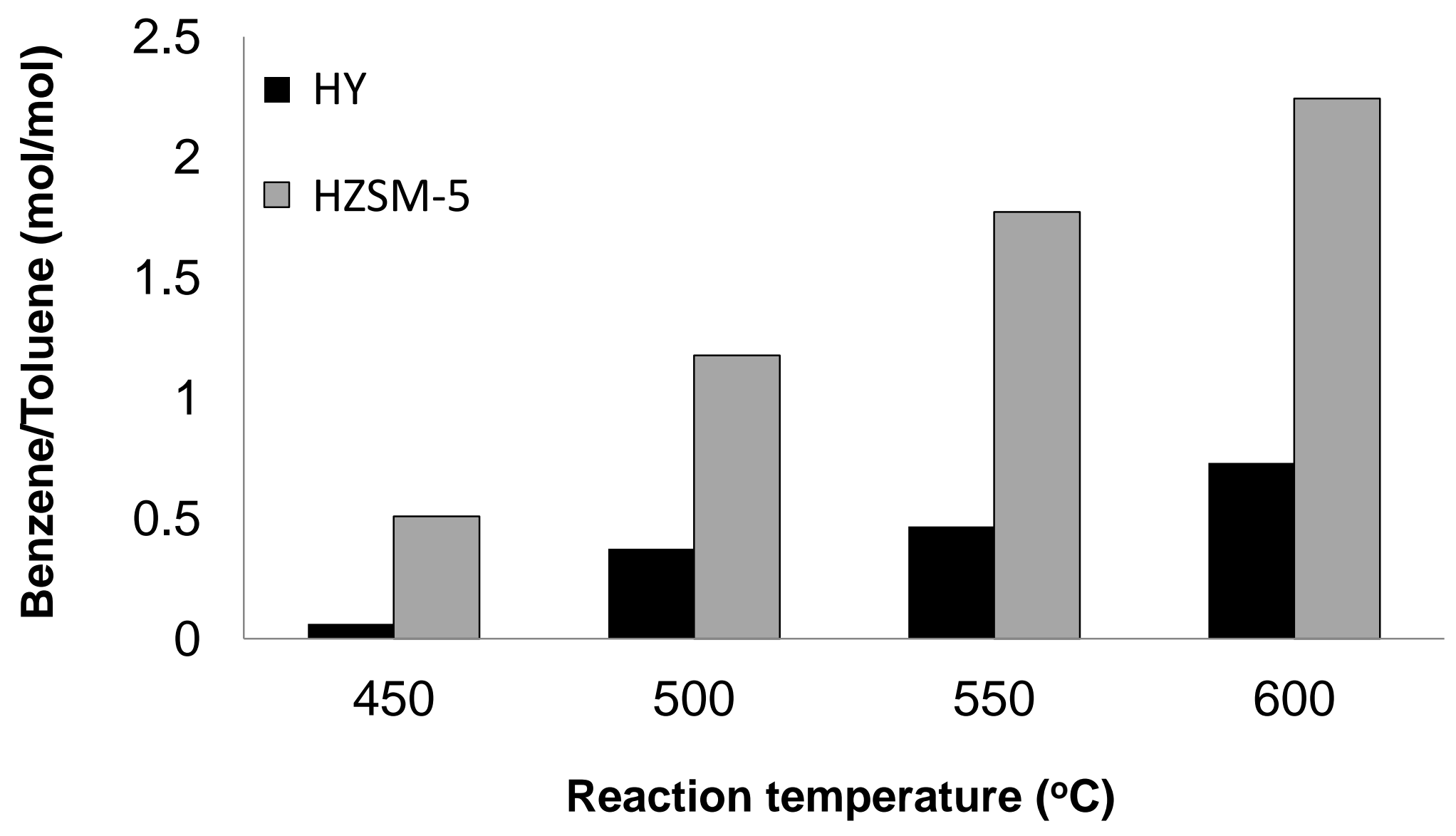

Figure 4. Molar ratio of benzene/toluene in m-cresol conversion over HY and HZSM-5 zeolites at different temperatures 
(a)

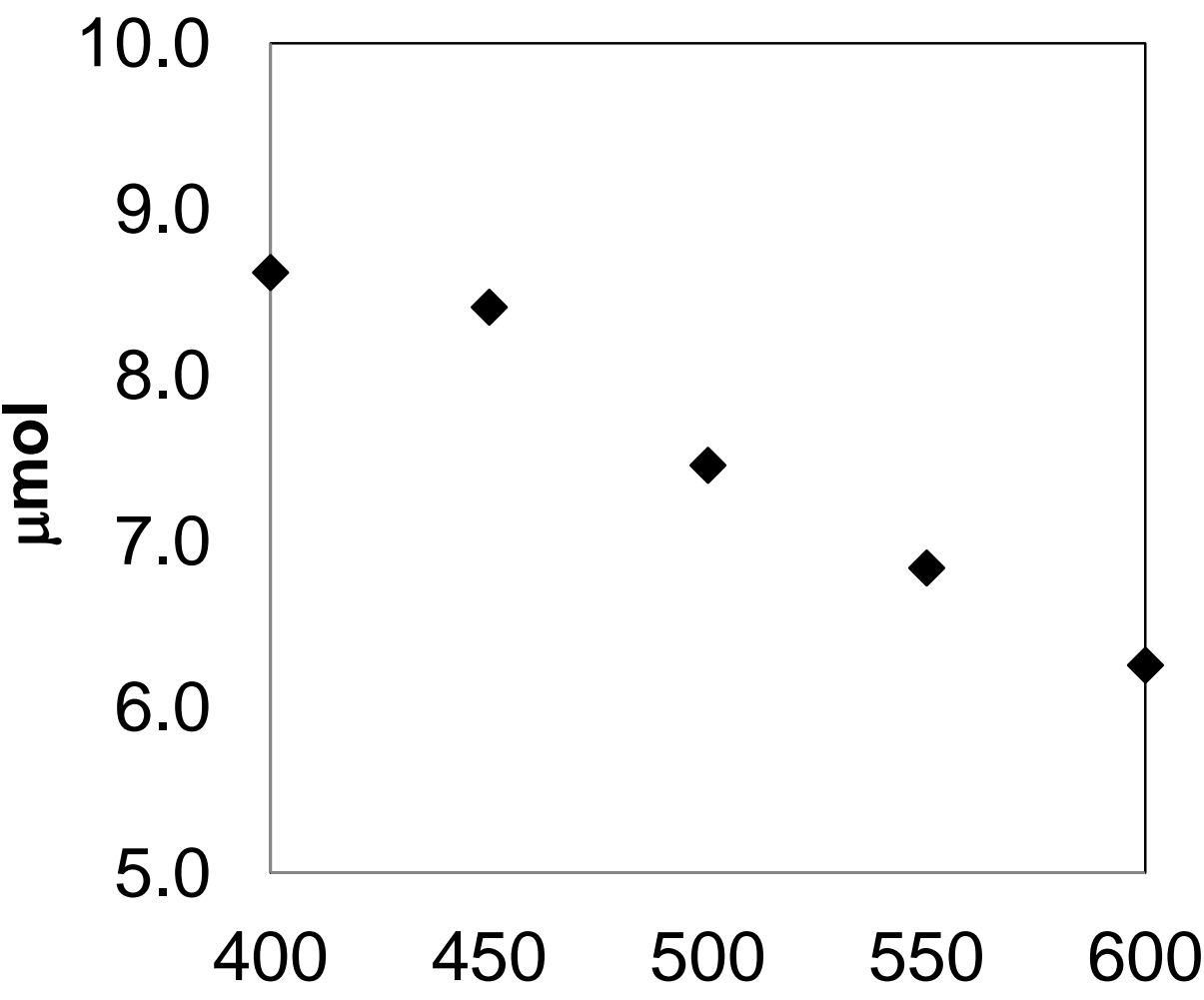

Reaction temperature $\left({ }^{\circ} \mathrm{C}\right)$ (b)

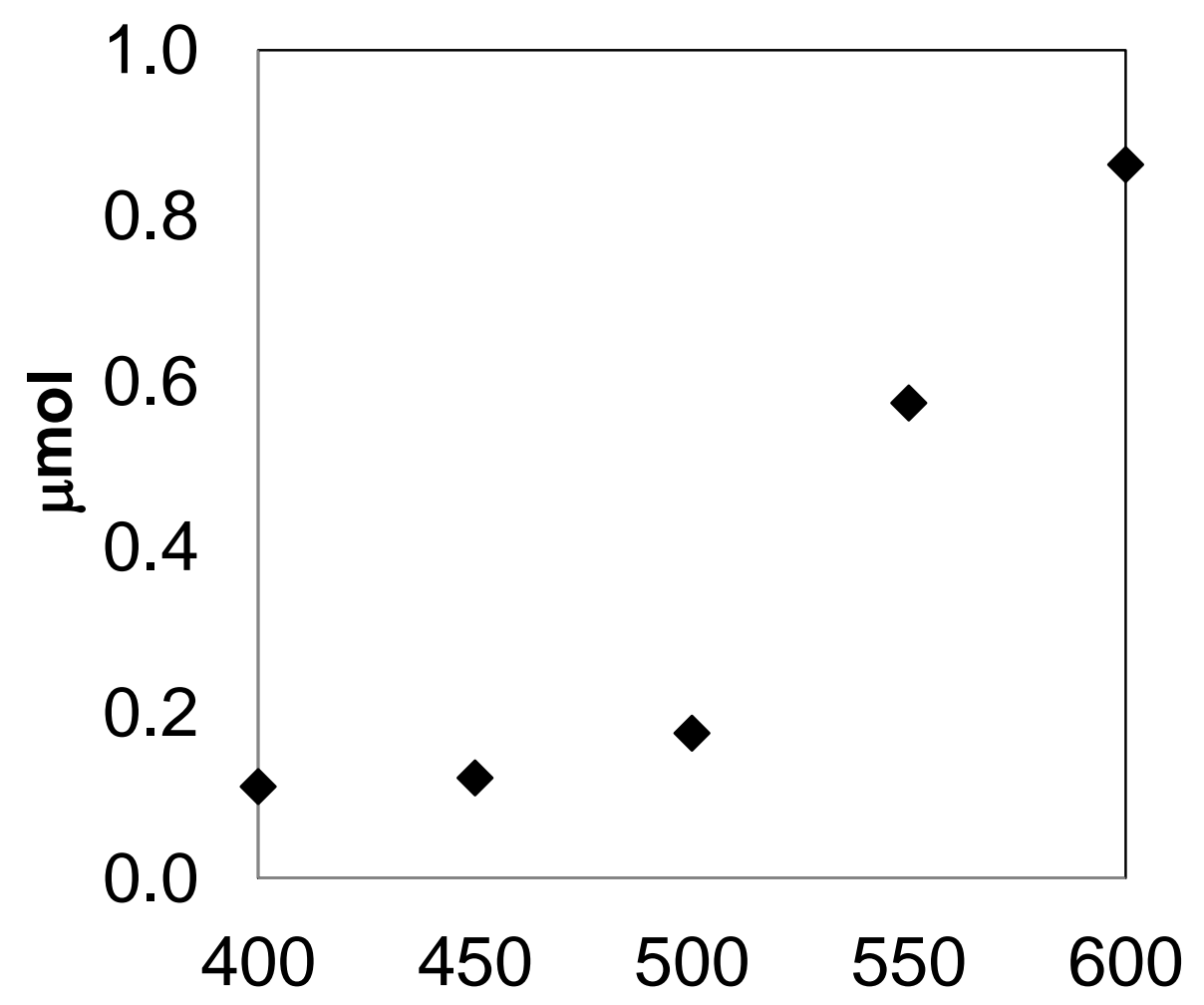

Reaction temperature $\left({ }^{\circ} \mathrm{C}\right)$

Figure 5. Amount of $C$ in the spent catalyst after (a) 9 pulses of $\mathrm{m}$-cresol $(0.15 \mu \mathrm{mol} / \mathrm{pulse})$ or (b) 20 pulses $n$-hexane ( $4 \mu \mathrm{mol} / \mathrm{pulse})$ over $100 \mathrm{mg}$ of HY zeolite at different temperatures 


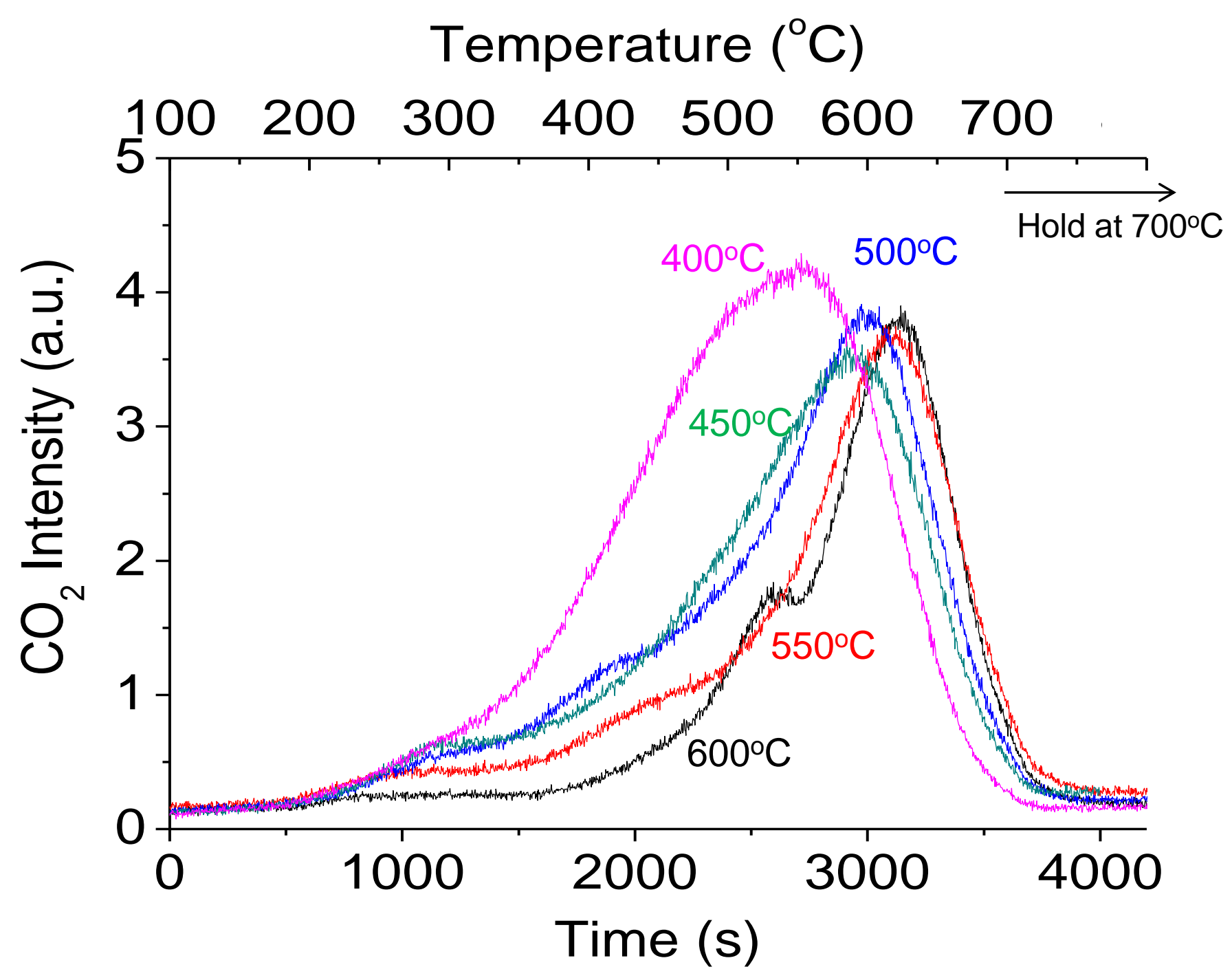

Figure 6. Evolution of $\mathrm{CO}_{2}(\mathrm{~m} / \mathrm{z}=44)$ during TPO of the spent catalyst after 9 pulses of $\mathrm{m}$ cresol over HZSM-5 zeolite at different reaction temperatures 
(a)

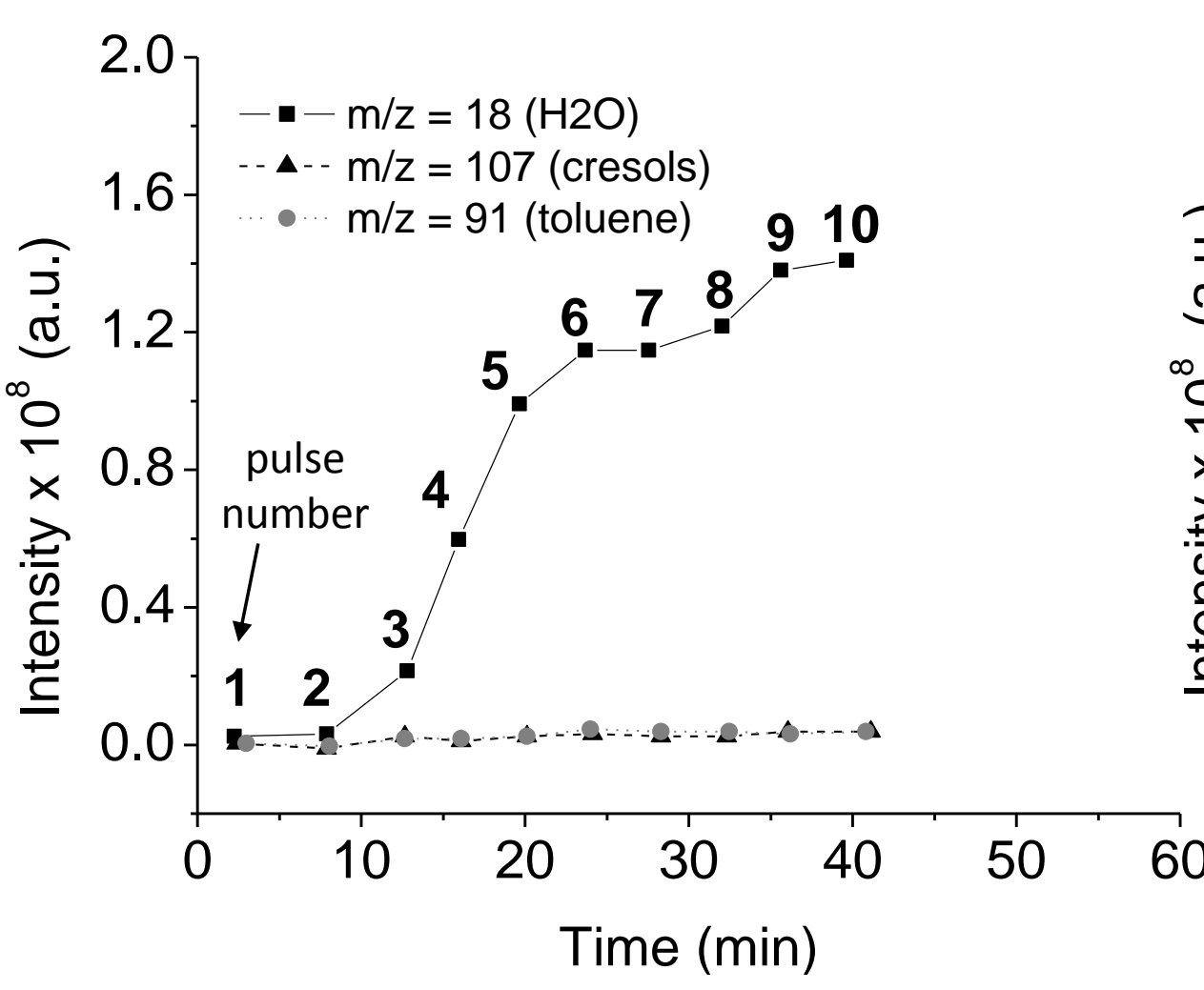

(b)

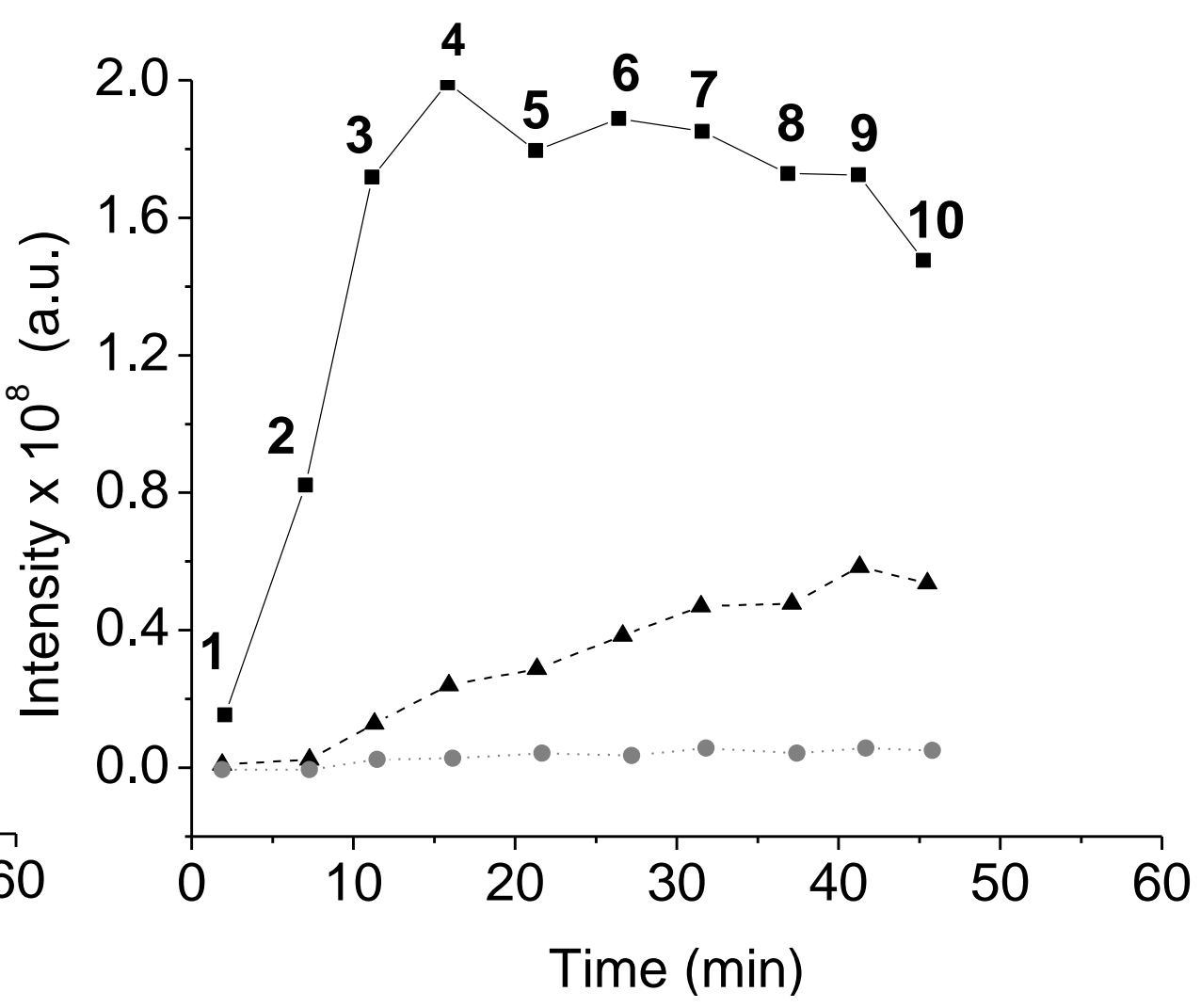

Figure 7. Evolution of $\mathrm{H}_{2} \mathrm{O}(\mathrm{m} / \mathrm{z}=18)$, cresols $(\mathrm{m} / \mathrm{z}=107)$ and toluene $(\mathrm{m} / \mathrm{z}=91)$ during pulses of m-cresol over (a) $100 \mathrm{mg}$ and (b) $50 \mathrm{mg}$ of HZSM-5 zeolite at $400{ }^{\circ} \mathrm{C}$ 
Temperature $\left({ }^{\circ} \mathrm{C}\right)$
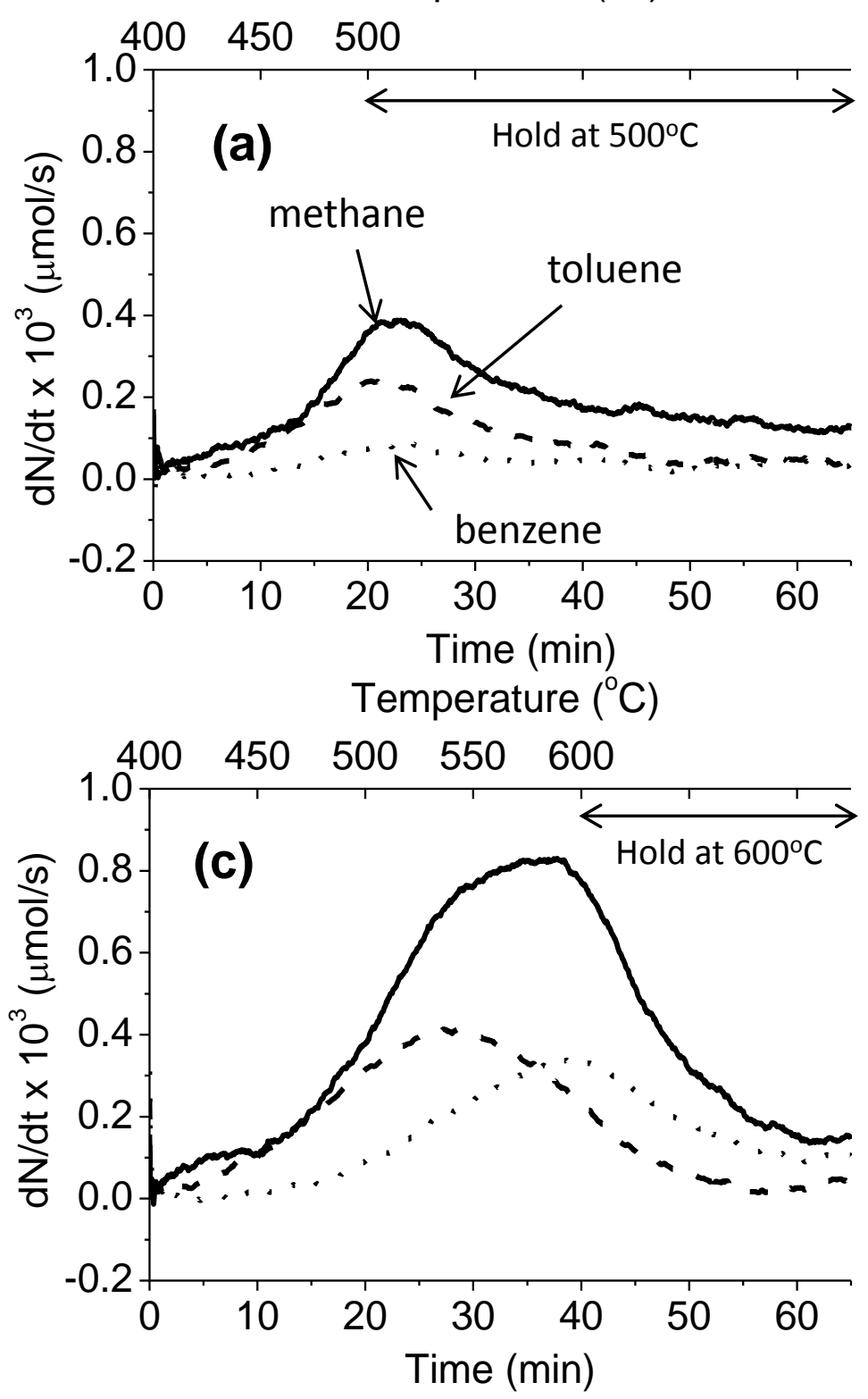

Temperature $\left({ }^{\circ} \mathrm{C}\right)$

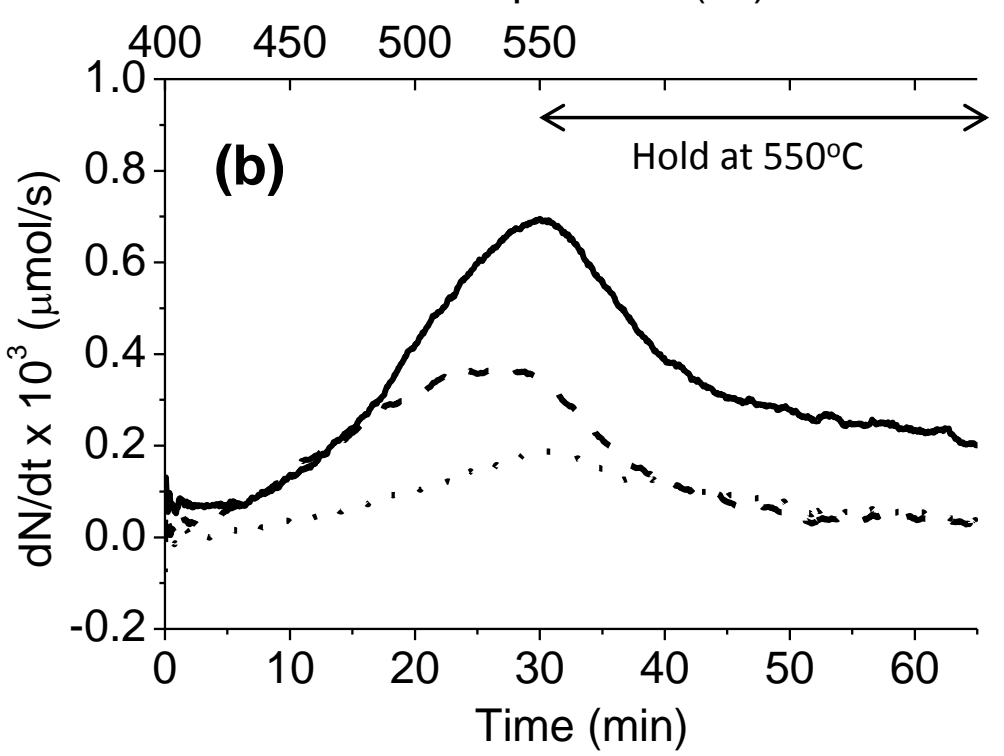

Temperature $\left({ }^{\circ} \mathrm{C}\right)$

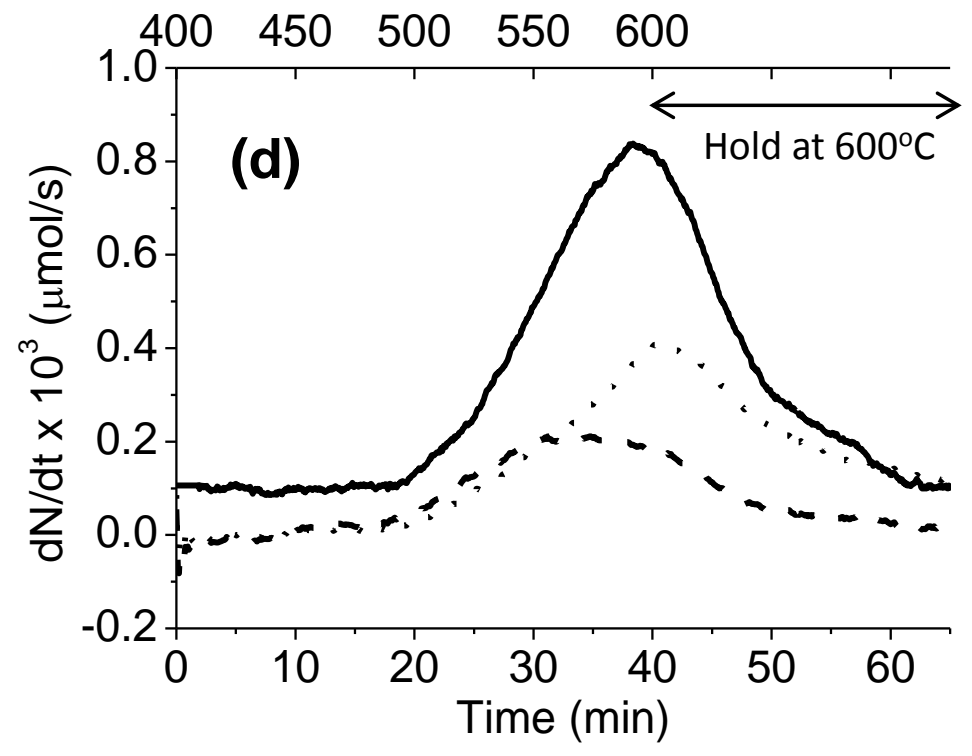

Figure 8. Temperature programmed decomposition of the phenolic pool formed by $\mathrm{m}$-cresol reaction at $400^{\circ} \mathrm{C}(\mathrm{a}-\mathrm{c})$ and $500^{\circ} \mathrm{C}$ (d) over $50 \mathrm{mg}$ of $\mathrm{HY}$ zeolite. A linear ramp of $5^{\circ} \mathrm{C} / \mathrm{min}$ from $400^{\circ} \mathrm{C}$ followed by isothermal hold period at (a) $500^{\circ} \mathrm{C}$, (b) $550^{\circ} \mathrm{C}$, (c) and (d) $600^{\circ} \mathrm{C}$. 


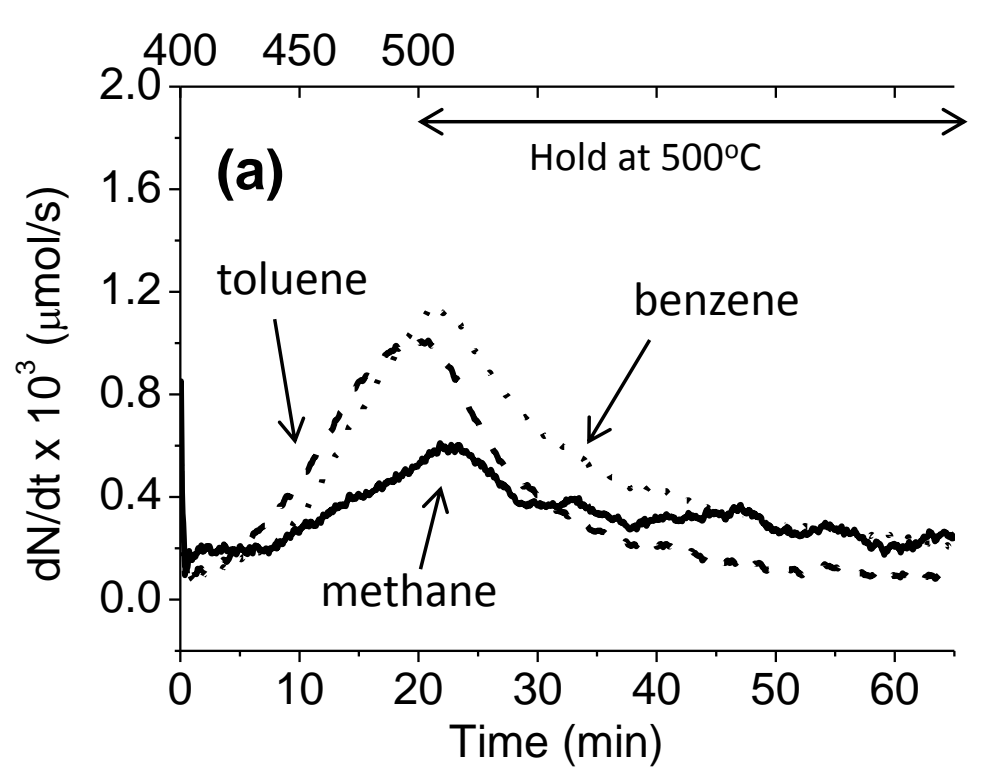

Temperature $\left({ }^{\circ} \mathrm{C}\right)$
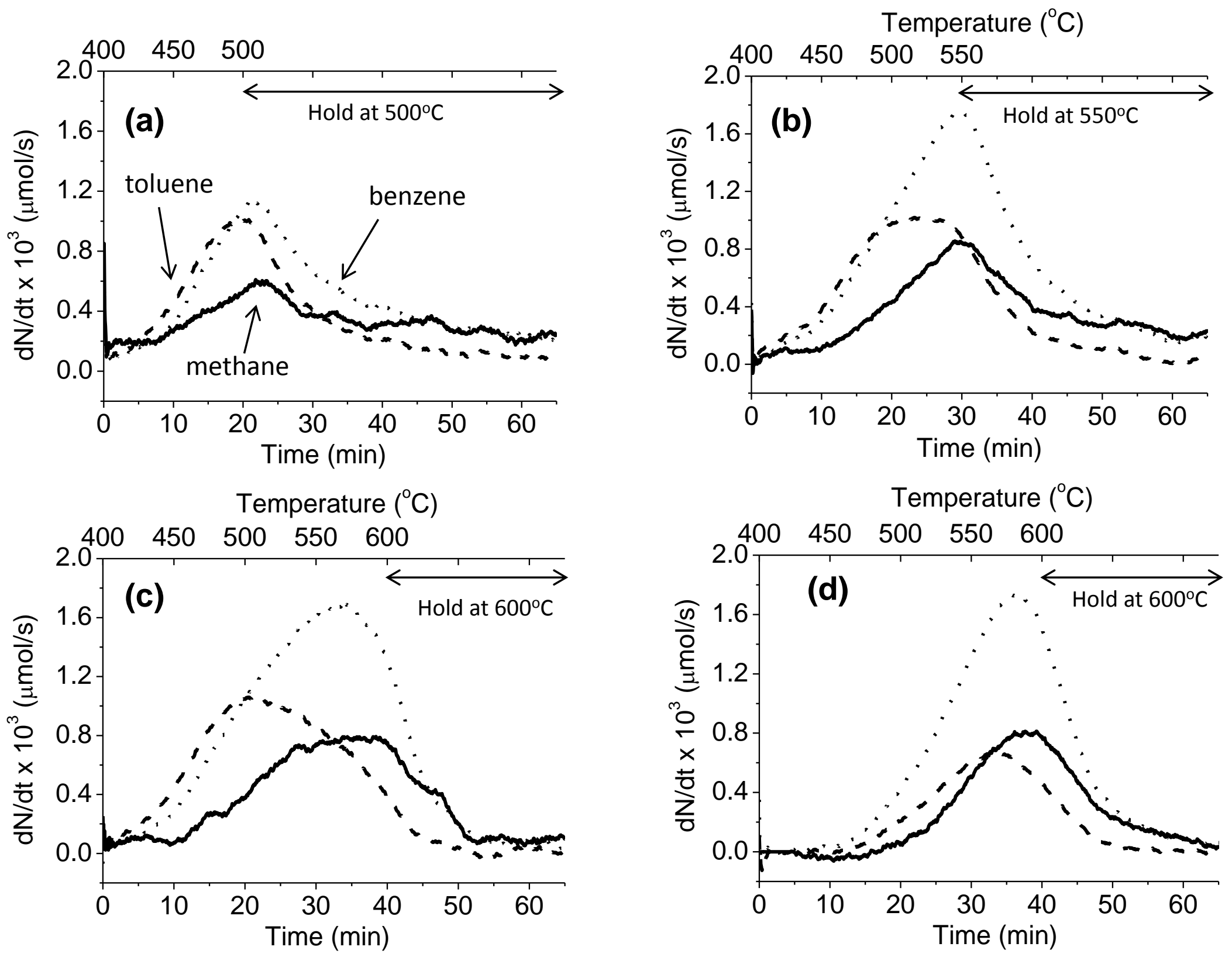

Figure 9. Temperature programmed decomposition of the phenolic pool formed by $\mathrm{m}$-cresol reaction at $400^{\circ} \mathrm{C}(\mathrm{a}-\mathrm{C})$ and $500^{\circ} \mathrm{C}$ (d) over $50 \mathrm{mg}$ of $\mathrm{HZSM}-5$ zeolite. A linear ramp of $5^{\circ} \mathrm{C} / \mathrm{min}$ from $400^{\circ} \mathrm{C}$ followed by isothermal hold period at (a) $500^{\circ} \mathrm{C}$, (b) $550^{\circ} \mathrm{C}$, (c) and (d) $600^{\circ} \mathrm{C}$. 


\begin{tabular}{|c|c|c|c|c|c|c|c|c|}
\hline Catalyst & $\begin{array}{c}\text { Iso- } \\
\text { thermal } \\
\text { hold }\left({ }^{\circ} \mathrm{C}\right)\end{array}$ & $\begin{array}{c}\text { Methane } \\
(\mu \mathrm{mol})\end{array}$ & $\begin{array}{c}\text { Benzene } \\
(\mu \mathrm{mol})\end{array}$ & $\begin{array}{c}\text { Toluene } \\
(\mu \mathrm{mol})\end{array}$ & $\begin{array}{c}\text { Benzene } \\
\text { Toluene }\end{array}$ & $\begin{array}{c}\text { Aromatic } \\
\text { yields from } \\
\text { decompo- } \\
\text { sition of the } \\
\text { pool } \\
(\mathbf{w t} \%)\end{array}$ & $\begin{array}{c}\text { Aromatic } \\
\text { yields from } \\
\text { pulse } \\
\text { experiment } \\
(\mathbf{w t \% )} * *\end{array}$ & From \\
\hline \multirow{2}{*}{ HY } & 500 & 0.3 & 0.04 & 0.2 & 0.20 & 1.62 & 4.78 & Fig. 8a \\
\cline { 2 - 9 } & 550 & 0.6 & 0.15 & 0.4 & 0.38 & 3.59 & 11.1 & Fig. 8b \\
\cline { 2 - 9 } & 600 & 1.0 & 0.35 & 0.55 & 0.64 & 5.80 & 16.1 & Fig. 8c \\
\hline \multirow{2}{*}{ HZSM-5 } & 500 & 0.3 & 1.2 & 1.0 & 1.20 & 11.75 & 18.98 & Fig. 9a \\
\cline { 2 - 9 } & 550 & 0.7 & 2.0 & 1.3 & 1.54 & 17.07 & 23.35 & Fig. 9b \\
\cline { 2 - 9 } & 600 & 1.0 & 2.4 & 1.4 & 1.71 & 20.49 & 31.21 & Fig. 9c \\
\cline { 2 - 9 } & $600(\mathrm{x} 2)^{*}$ & 2.5 & 5.0 & 2.8 & 1.79 & 42.44 & & \\
\hline
\end{tabular}

* The catalyst amount was doubled (100mg)

** Reaction conditions were described in part 3.1

Table 1. Product formation ( $\mu \mathrm{mol}$ ) from temperature programmed decomposition of the phenolic pool formed during m-cresol reaction at $400^{\circ} \mathrm{C}$ over $50 \mathrm{mg}$ of $\mathrm{HY}$ and $\mathrm{HZSM}-5$ zeolites $(\mathrm{Si} / \mathrm{Al}$ ratio $=40)$. 


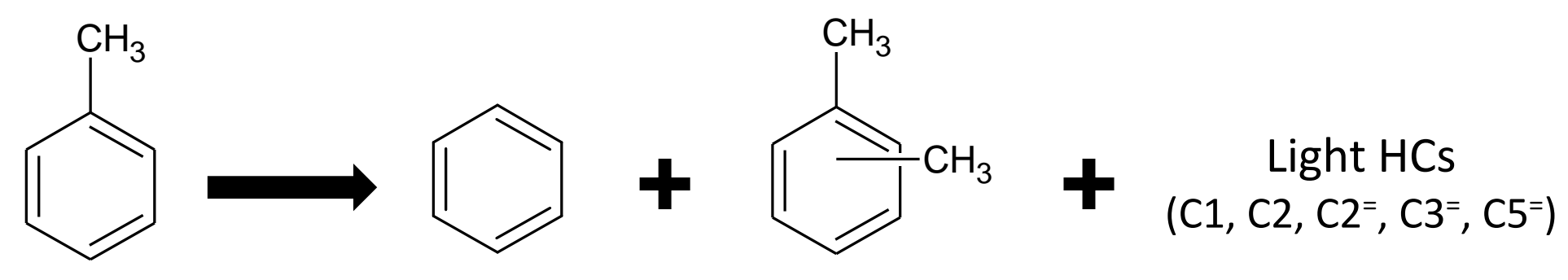

\begin{tabular}{|c|c|c|c|c|}
\hline \multirow{2}{*}{ Catalysts } & \multirow{2}{*}{ Conversion } & \multicolumn{3}{|c|}{ Product yields (wt\%) } \\
\cline { 3 - 5 } & & Benzene & Xylenes & Light hydrocarbons \\
\hline No catalyst & 0.3 & 0 & 0.06 & 0.26 \\
\hline HY & 11.5 & 5.2 & 6 & 0.25 \\
\hline HZSM-5 & 28.5 & 12.2 & 16 & 0.24 \\
\hline
\end{tabular}

Table 2. Conversion and product yields from toluene thermal cracking or catalytic cracking reactions over $50 \mathrm{mg}$ of $\mathrm{HY}$ or $\mathrm{HZSM}-5$ zeolite at $600^{\circ} \mathrm{C}$.

Results of the first pulse on a fresh catalyst. 


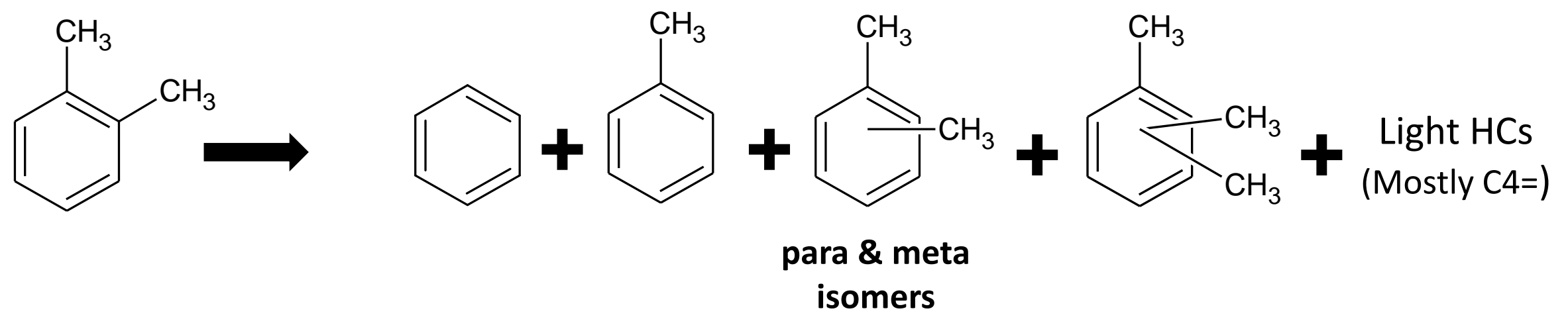

\begin{tabular}{|c|c|c|c|c|c|c|}
\hline \multirow{2}{*}{ Catalysts } & \multirow{2}{*}{ Conversion } & \multicolumn{5}{|c|}{ Product yields (wt\%) } \\
\cline { 3 - 7 } & & Benzene & Toluene & $\begin{array}{c}\text { p- and m- } \\
\text { xylenes }\end{array}$ & $\begin{array}{c}\text { Trimethyl } \\
\text { benzenes }\end{array}$ & $\begin{array}{c}\text { Light } \\
\text { hydrocarbons }\end{array}$ \\
\hline HY & 63 & 0.1 & 5 & 52 & 5.7 & 0.2 \\
\hline HZSM-5 & 72.3 & 0.9 & 2.8 & 59.8 & 8.5 & 0.2 \\
\hline
\end{tabular}

Table 3. Conversion and product yields from o-xylene reaction over $10 \mathrm{mg}$ of $\mathrm{HY}$ or HZSM-5 zeolite at $600^{\circ} \mathrm{C}$. Results of the first pulse on a fresh catalyst. 


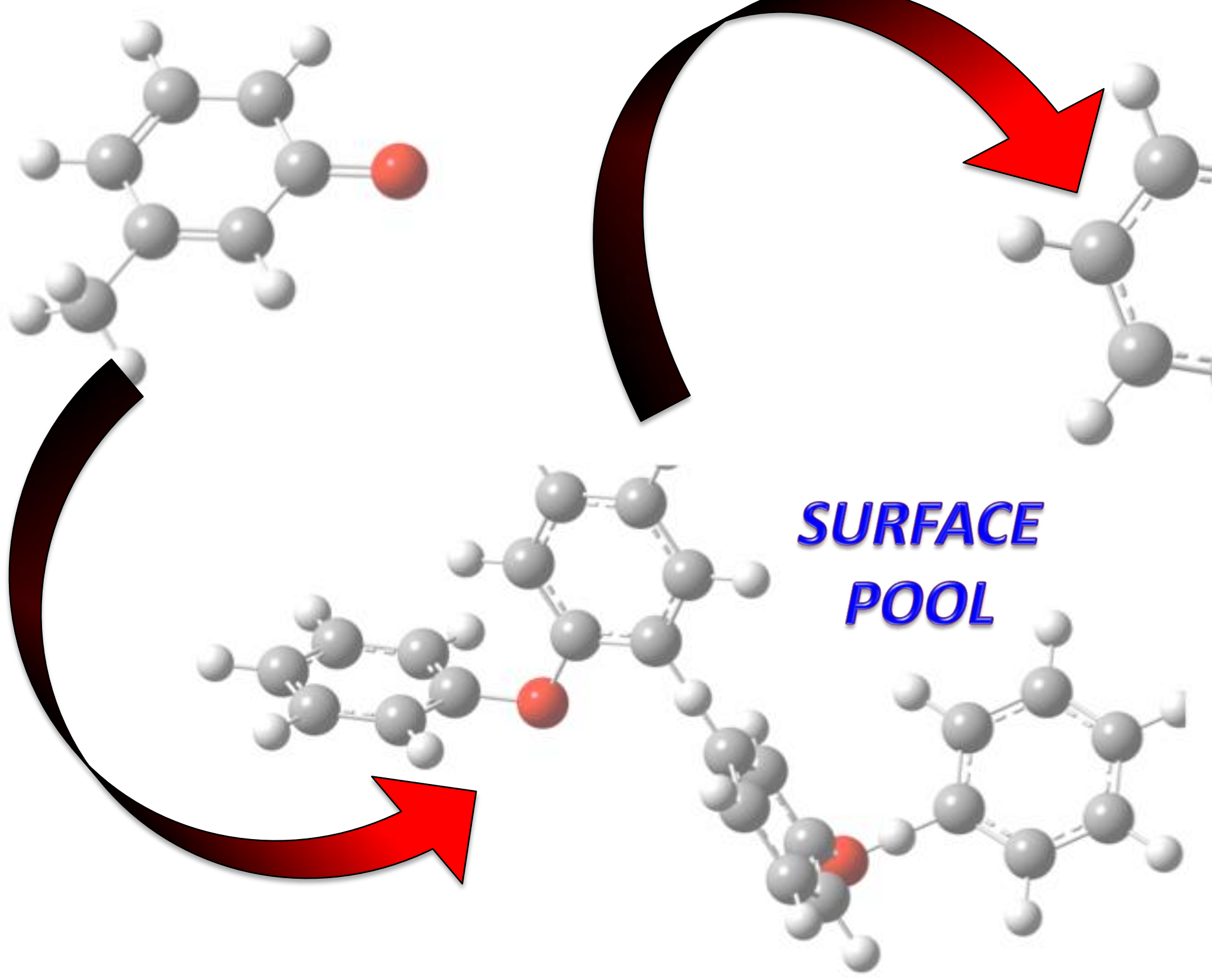

